\title{
Development of the VTUF-3D v1.0 urban micro-climate model to support assessment of urban vegetation influences on human thermal comfort
}

\author{
Kerry A. Nice ${ }^{\mathrm{a}, \mathrm{b}, \mathrm{c}, \mathrm{w}}$, Andrew M. Coutts ${ }^{\mathrm{a}, \mathrm{c}}$, Nigel J. Tapper ${ }^{\mathrm{a}, \mathrm{c}}$ \\ ${ }^{a}$ School of Earth, Atmosphere and Environment, Monash University, Clayton, Victoria 3800, Australia \\ ${ }^{b}$ Transport, Health, and Urban Design Hub, Faculty of Architecture, Building, and Planning, University of Melbourne, Victoria 3010, Australia \\ ${ }^{c}$ Cooperative Research Centre for Water Sensitive Cities, Melbourne, Australia
}

\begin{abstract}
With urban areas facing longer duration heat-waves and temperature extremes from climate change and growing urban development, adaptation strategies are needed to protect city residents. Examining the role that increased tree cover and water availability can have on human thermal comfort (HTC) is needed to help guide the development of thermally comfortable cities. To inform planning, modelling tools are needed that provide sufficient resolution to resolve urban influences on HTC and the ability to model important physiological processes of vegetation. To achieve this, a new micro-scale model, VTUF-3D (Vegetated Temperatures of Urban Facets) has been developed. In it, offline modelling of individual items of vegetation is performed using the MAESPA process-based tree model (Duursma and Medlyn, 2012) (a model that can model individual trees, vegetation, and soil components), and integrated into the TUF-3D (Krayenhoff and Voogt, 2007) urban micro-climate surface energy balance (SEB) model. This innovative approach allows the new model to account for important vegetative physiological processes and shading effects, using configurable templates to allow representation of any type of vegetation or water sensitive design feature. This work enables detailed calculations of surface temperatures $\left(T_{s f c}\right)$, mean radiant temperature $\left(T_{m r t}\right)$, and a HTC index, the universal thermal climate index (UTCI), across urban canyons. This study presents an overview of VTUF-3D. Also presented are two evaluations of VTUF-3D. The first evaluation compares modelled surface energy balance fluxes to observations in Preston, Australia (Coutts et al., 2007). The second evaluation compares spatial and temporal predictions of $T_{m r t}$ and UTCI to two observed street canyons in the City of Melbourne (Coutts et al., 2015b). The VTUF-3D model is shown to perform well and is suitable for use to examine critical questions relating to the role of vegetation and water in the urban environment in support of HTC.
\end{abstract}

Keywords: micro-climate modelling, urban vegetation, VTUF-3D, human thermal comfort, mean radiant temperature, UTCI

\section{Introduction}

Urban areas are facing a growing number of challenges. Cities are now home to the majority of the world's population and trends will result in further growth (UNDESA, 2015; WHO, 2016). To accommodate increasing urban populations, cities are expanding (Seto et al., 2011) and densifying (Byrne et al., 2016; Ruth and Coelho, 2016; DSE, 2002), leading to loss of urban green spaces (Hamin and Gurran, 2009; Coutts et al., 2007). In these increasingly urbanised areas, the removal of vegetation, combined with rapid stormwater removal and possibly restricted irrigation during drought conditions, can leave urban landscapes water starved. Urban development that does not consider the implications on urban climate, risks intensifying urban heating and compromising the thermal comfort of city residents. In addition, climate trends point towards increasing average and extreme temperatures (Alexander and Arblaster, J, 2009; IPCC, 2013). These trends are concerning given the growing understanding of the impacts on human health of extreme temperatures (Katsouyanni et al., 1993; Nicholls et al., 2008; Loughnan et al., 2010)

\footnotetext{
* Principal corresponding author

Email address: mothlight@fastmail.fm (Kerry A. Nice)
} 


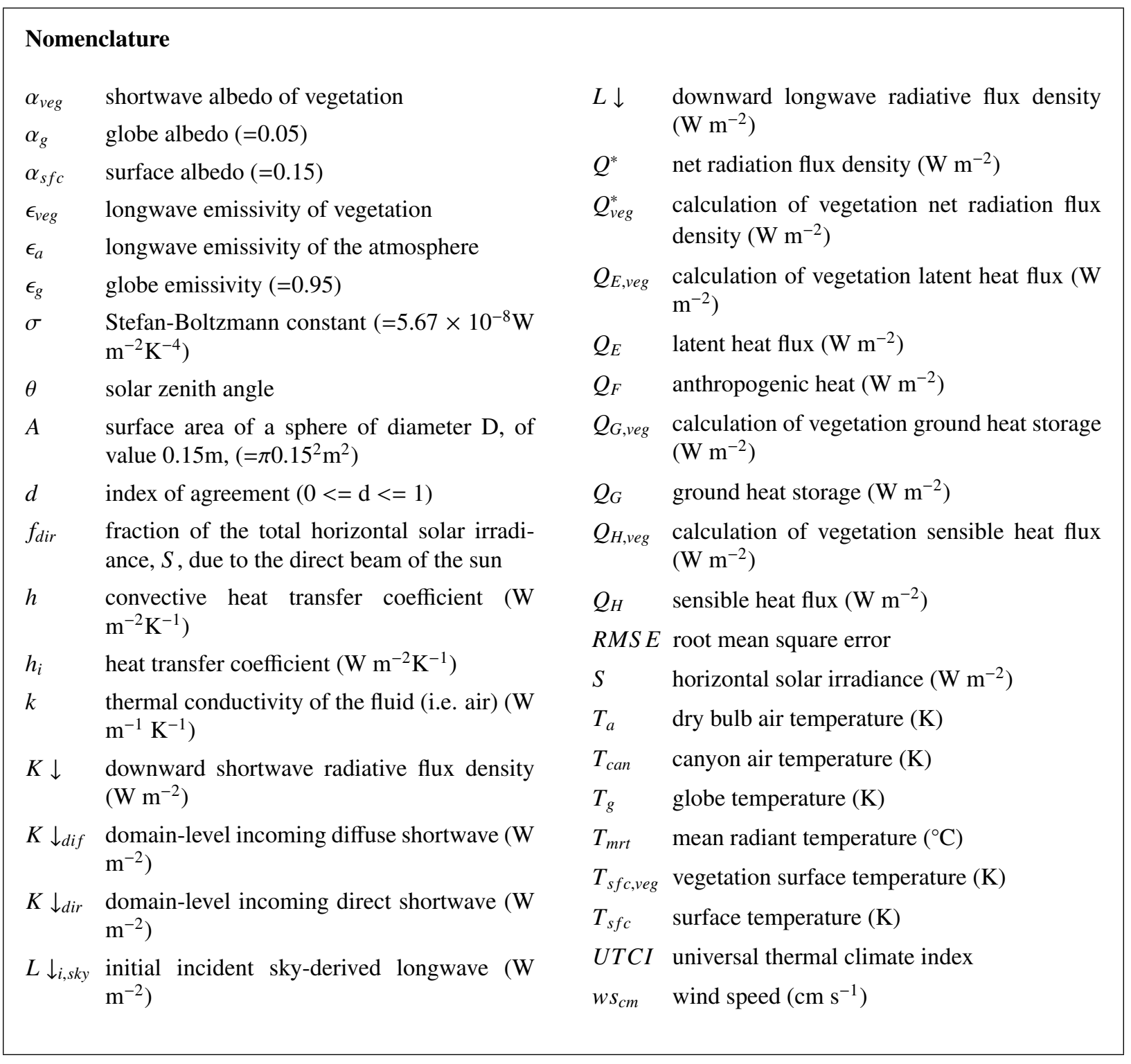

and demographics that are shifting toward a more elderly population (Cohen, 2003; Federal Interagency Forum on Aging-Related Statistics, 2016) that is particularly vulnerable to extreme heat, and leave those in urban areas in an increasingly dangerous position. In coming years, cities and their residents will need to adapt to these challenges.

Incorporating more vegetation and water into urban areas can effectively mitigate extreme urban temperatures at local to micro scales (Tsiros, 2010; Shashua-Bar et al., 2010; Spangenberg and Shinzato, 2008; Coutts et al., 2012). Shading and evapotranspiration are cited as the main drivers of these cooling effects (Bowler et al., 2010). The degree of cooling effects are variable however, and depend on factors such as vegetation density (Hall et al., 2016; Bodnaruk et al., 2017), street orientation and aspect ratio (Thorsson et al., 2011; Ali-Toudert and Mayer, 2006), and amounts of irrigation used (Jenerette et al., 2011). Trees in particular provide a strong benefit for HTC during the day, especially those with large, dense canopies that provide shade and are well irrigated to promote transpiration (Coutts et al., 2015b; Huang et al., 2008; Ylmaz et al., 2007; Shashua-Bar and Hoffman, 2000), with possible additional side benefits of reduced energy usage (and associated emissions and anthropogenic heat) for cooling (Donovan and Butry, 2009; Rosenfeld et al., 1996; Simpson and McPherson, 1993) by strategically placed trees. Water sensitive 
urban design (WSUD) presents an opportunity to capture and retain stormwater in urban areas using engineered and natural features (trees, vegetation, and substrate) to capture, filter, and store water as an additional urban water source (Wong and Brown, 2009). A more focused effort in using trees and WSUD for urban climate benefits can deliver improvements to human thermal comfort (HTC) (Coutts et al., 2012).

While the benefits of urban vegetation and water are well understood in the climate community, uptake and application of knowledge in urban planning is lacking. Bowler et al. (2010) suggests that the current research does not demonstrate exactly how urban greening should be implemented in terms of abundance, type, and distribution. A suitable modelling tool is needed to provide solid quantitative assessments of the effectiveness of trees and water in terms of heat mitigation, across contrasting micro-scale urban environments, and therefore provide guidance on how to most effectively use trees and WSUD for improved HTC.

A suitable modelling tool for these assessments needs to resolve detailed temperature gradients (as well as wind speed and humidity in order to calculate HTC) across a modelled urban canyon, requiring micro-scaled resolution climate modelling. In addition, modelling needs to incorporate important cooling mechanisms of evapotranspiration and shading. Accounting for these effects requires proper modelling of vegetation, including vegetation physiology to estimate accurate latent energy fluxes and the soil-vegetation-atmosphere pathway critical for vegetation and WSUD assessments within the urban canyon. Models such as SOLWEIG (Lindberg et al., 2008) and RayMan (Matzarakis et al., 2007, 2010) resolve at a suitable scale and generate useful insights into mean radiant temperatures in urban areas (Chen et al., 2014), only capture the radiation shading effects of vegetation, and are unable to account for the effects of water and evapotranspiration. At the other end of the complexity spectrum, a number of models, primarily based on computational fluid dynamics (CFD), are able to resolve at a micro-scale and account for many of the influences of vegetation (Bailey et al., 2014, 2016; Kunz et al., 2000; Schlünzen et al., 2011; Yamada and Koike, 2011; Bruse, 1999). However their complexity and computational intensity puts them out of reach for less specialised users.

What is needed is an approach that fits in between these two levels of complexity, a new innovative method to balance detail, accuracy, and complexity with efficiency and usability, while also being able to consider a wide variety of vegetation types and arrangements. The approach also needs to balance complexity against usability to create a model that can be widely used to consider a large variety of questions about HTC impacts of urban vegetation in support of urban planning decisions and guidelines.

This study presents the development of a new model, VTUF-3D (Vegetated Temperatures of Urban Facets in 3D v1.0), with the aim of providing a model capable of assessing the benefits of vegetation (including trees) and WSUD on urban canopy layer air temperatures and HTC. VTUF-3D is developed from the TUF-3D (Temperatures Of Urban Facets in 3D) model (Krayenhoff and Voogt, 2007) that prior to this work lacked vegetation and water components. The TUF-3D model was coupled with the MAESPA model (an amalgamation of the MAESTRO (not an acronym) and SPA (Soil-plant-atmosphere) models) (Duursma and Medlyn, 2012), allowing insertion of any type of vegetation in any arrangement into a modelling domain, to account for vegetation structural and physiological processes. This study also aims to evaluate the model, in terms of the surface energy balance, for an urban site in Melbourne, Australia, and against micro-climate observations of $T_{m r t}$ and UTCI recorded across two streets (with differing canopy cover) in the City of Melbourne. As a point of comparison with other models at this scale, VTUF-3D calculates a 30 day simulation using hourly timesteps of a $200 \times 200 \mathrm{~m}$ area with $5 \mathrm{~m}$ resolution on a standard desktop computer in an hour or two (at least an order of magnitude less time than required by a CFD based model).

VTUF-3D has the capacity to address the research gap identified by Bowler et al. (2010) of how vegetation (especially trees) should be best implemented in terms of abundance, type and distribution, as well as the potential for accounting for water availability through WSUD. Analysis from VTUF-3D can facilitate the integration of urban greening into the urban landscapes and inform planning decisions, with urban climate knowledge, about how to best utilise urban greening to maximise the thermal comfort impacts and meet the challenges of urban heat.

\section{Model design}

\subsection{Overview of the VTUF-3D model}

VTUF-3D is constructed using the TUF-3D model, as described in Krayenhoff and Voogt (2007), leaving all its components largely unchanged except for the two interactions described in this overview of changes. The ability to include vegetation in modelling scenarios is added through the integration of the MAESPA model (Duursma and 
Medlyn, 2012). Two major changes were made to the TUF-3D model to add this missing functionality. The first is the representation of the physical form of vegetation and the associated radiative interactions within an urban canyon. VTUF-3D uses cube shaped structures (as TUF-3D uses to represent buildings) to also represent vegetation. A single tower of cubes forms the tree trunk at the $\mathrm{x}, \mathrm{y}$ location of the tree and extends upward to the height of the tree. If a canopy extends past the surface grid square boundaries, additional cubes are allowed to overhang (and shade) the ground surface to fill out the full width of the canopy. These cubes store the surface properties and states and interact with the rest of the VTUF-3D domain. The true shape of the vegetation (e.g. ellipsoidal, conical, etc.) is represented in MAESPA, with each vegetation element individually modelled offline, calculating values of vegetation absorption, transmission, and reflection to be loaded by VTUF-3D as needed in a simulation (Figure 1).

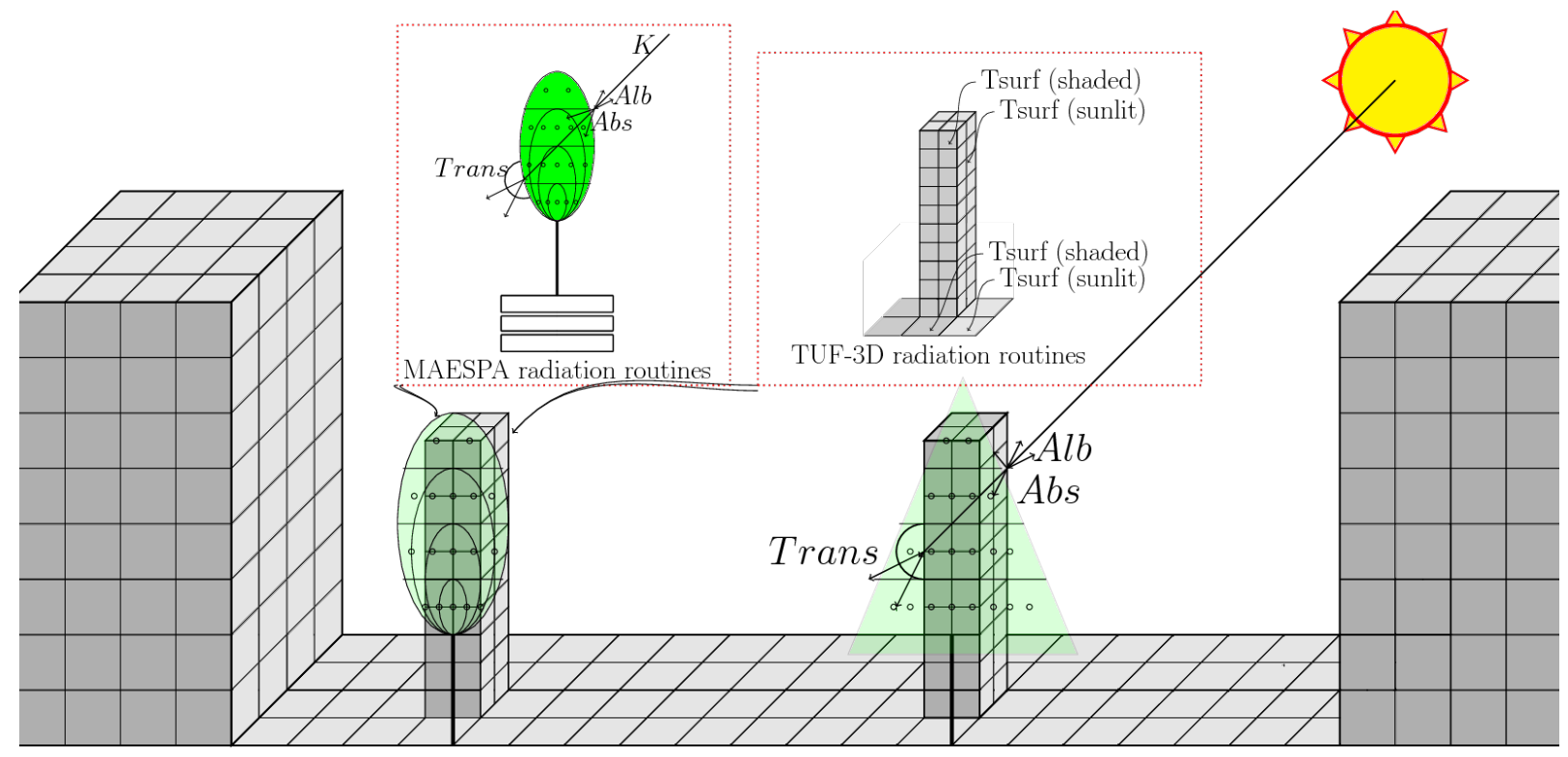

Figure 1: Integration of the tree model MAESPA into VTUF-3D radiation fluxes routines, in which tiled instances of MAESPA vegetation (in green) are used to calculate radiation transmission for VTUF-3D placeholder vegetation structures (in grey).

The second major change required is including the physiological processes of vegetation and soil in the model. Using a novel approach, MAESPA tiles replace VTUF-3D ground surfaces with vegetated MAESPA surfaces and use results of MAESPA's photosynthesis and water balance routines to modify VTUF-3D's energy balance calculations. The vegetation is treated as a flat two dimensional ground surface tile for the surface energy balances. However, each embedded MAESPA surface actually models a full 3-dimensional tree (along with associated soil and vertical movement of water) and feeds results back to VTUF-3D ground surface energy balances (Figure 2). Each grid cell is assumed to hold a single item of vegetation but can theoretically hold multiple items, as supported by MAESPA. In addition, VTUF-3D allows tree canopies to extend into neighbouring grid squares (overhanging the ground, wall, and roof surfaces contained in them and casting shade), so can handle any grid resolution and properly model canopies containing individual trees that exceed the grid size.

At the conclusion of each timestep (default of 30 minutes but duration is user configured), VTUF-3D calculates the energy balance of each surface. Tiles of MAESPA instances (with an individual tree or other types of vegetation in each) are used for surfaces that have vegetation (Figure 2). These instances provide values of radiation transmission, energy fluxes (including latent energy, not previously accounted for in TUF-3D), and soil water storage for each item of vegetation in the domain using their unique properties and characteristics. If a surface does not contain vegetation, VTUF-3D runs TUF-3D's normal energy balance calculations.

\subsection{Radiative transfer}

In order to track the movement and allocation of radiation, VTUF-3Ds modelling domain is built up in 3D using cubes and their surfaces (facets). To determine which surfaces can 'see' each other (unobstructed by other surfaces), 


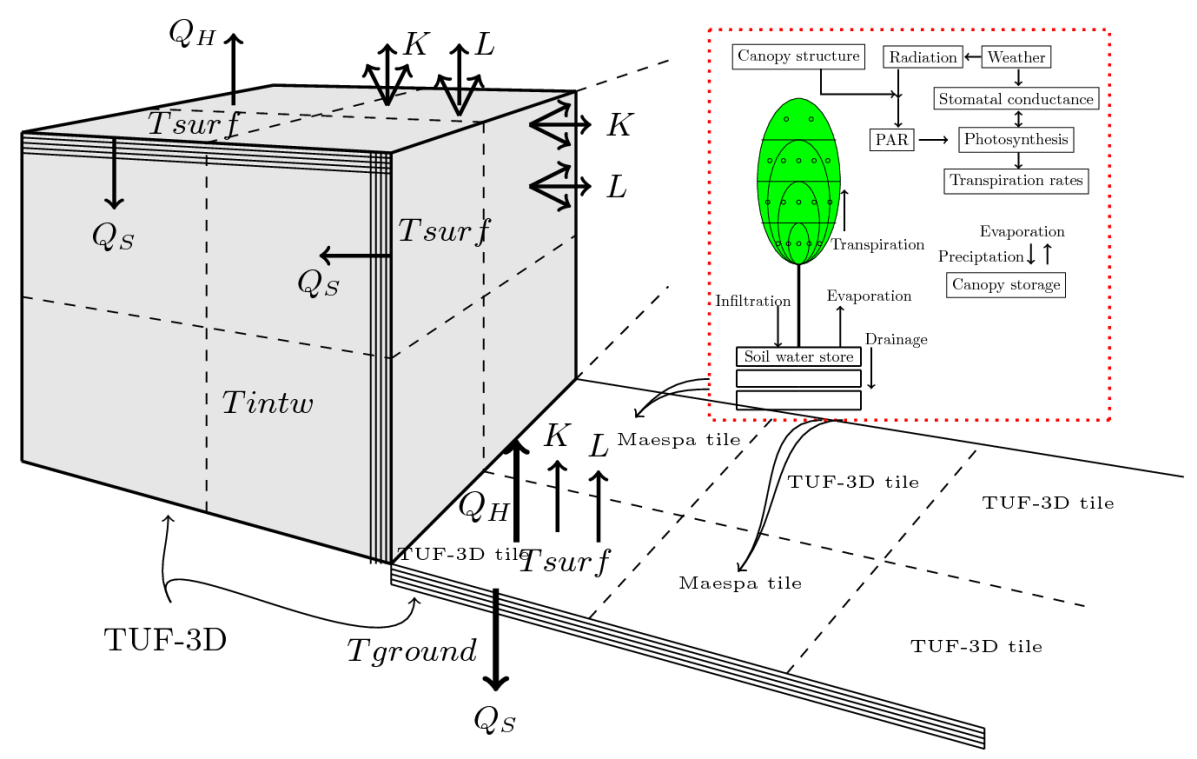

Figure 2: In VTUF-3D energy balance modelling, ground surfaces can contain either regular TUF-3D surfaces or a surface containing MAESPA modelled vegetation. All surfaces will calculate energy balances at the conclusion of each timestep, partitioning available energy into radiative, sensible, latent, and storage fluxes. Those surfaces with vegetation will also account for vegetation physiological processes when performing energy balances.

ray tracing eliminates pairs of surfaces that will not need to be considered during simulations. Ray tracing also determines sunlit and shaded patterns on the 3D urban surfaces throughout a simulation using a modified version of the Soux et al. (2004) algorithm. Reflections and absorption of longwave and shortwave radiation are modelled using a radiosity approach (radiative reflection and emission treated as perfectly diffuse). These radiative transfer calculations are unchanged from the original TUF-3D scheme and are detailed in Krayenhoff and Voogt (2007).

For vegetated parts of the domain, radiative transfer is calculated by components from MAESPA. Incoming radiation, both photosynthetic radiation (PAR) and near infrared (NIR) is partitioned into direct and diffuse using the approach of Weiss and Norman (1985). Canopy structure is calculated based on Wang and Jarvis (1990), supporting a variety of crown shapes namely: conical, half-ellipsoidal, ellipsoidal and paraboloidal. Absorption and scattering of radiation (PAR, NIR, and thermal radiation) by the canopy is calculated using Norman (1979). Full details of these calculations are included in Duursma and Medlyn (2012). VTUF-3D accounts for the transmitted and absorbed quantities (as detailed in Section 2.5.1), but scattered quantities are currently disregarded by VTUF-3D.

In the calculation of net radiation $\left(Q_{v e g}^{*}\right)$ for vegetated grid squares, the TUF-3D calculated $T_{s f c}$ is replaced by MAESPA calculated vegetation surface temperatures $\left(T_{s f c, v e g}\right)$

$$
Q_{v e g}^{*}=K \downarrow-\left(\alpha_{v e g} K \downarrow\right)+\epsilon_{v e g} L \downarrow-\epsilon_{v e g} \sigma\left(T_{s f c, v e g}\right)^{4}
$$

where $K \downarrow$ is the downward shortwave radiative flux density ( $\mathrm{W} \mathrm{m}^{-2}$ ), $L \downarrow$ is the downward longwave radiative flux density $\left(\mathrm{W} \mathrm{m}^{-2}\right), \alpha_{\text {veg }}$ of vegetation is set to 0.20 and $\epsilon_{\text {veg }}$ of vegetation set to 0.97 (Oke, 1987, p. 12), $\sigma$ is the Stefan-Boltzmann constant $\left(=5.67 \times 10^{-8} \mathrm{~W} \mathrm{~m}^{-2} \mathrm{~K}^{-4}\right)$, and $T_{s f c, v e g}$ is the vegetation surface temperature $(\mathrm{K})$.

\subsection{Convective energy fluxes}

As the simulation proceeds through each timestep, an energy balance is performed on each surface. For each surface with vegetation, the surface temperature $\left(T_{s f c}\right)$ is set to the value calculated by MAESPA for that tree replacing the TUF-3D calculated value. Using this new value, the following describes modifications to the TUF-3D methods used to partition the energy fluxes of a vegetated surface. 


\subsubsection{Latent energy fluxes}

For latent energy fluxes, $Q_{E, v e g}$ is calculated for each grid square, loaded from offline MAESPA-modelled data for the individual item of vegetation and accompanying soil in the domain. These methods are fully described in Duursma and Medlyn (2012) and Medlyn et al. (2007), but will be highlighted here briefly. MAEPSA uses a number of variations of the Ball-Berry type approach (Ball et al., 1987; Duursma and Medlyn, 2012) for stomatal conductance. Canopy transpiration and leaf temperature for a MAESPA tile is calculated using an iterative scheme based on Wang and Leuning (1998). The Penman-Monteith equation (Penman, 1948; Monteith, 1965) is applied to each grid point (to account for variations due to sunlit and shaded portions of the canopy) and summed over all the grid points to calculate transpiration. Finally, leaf temperature is found by iteratively closing the energy balance of the leaf, based on Wang and Leuning (1998). MAESPA also accounts for water balance functionality. In MAESPA, infiltration is based on a function from the BROOK90 model (Federer et al., 2003). Soil evaporation is based on models developed by Choudhury and Monteith (1988) and Williams et al. (2001). Canopy interception of precipitation uses the Rutter et al. (1975) rainfall interception model. Finally, hydraulics of the soil-to-leaf pathway are estimated using the single root model of Gardner (1960).

VTUF-3D combines MAESPA-predicted canopy transpiration and soil evaporation values into a total $Q_{E}$ amount for each vegetated tile. MAESPA outputs values of storage of intercepted rain (canopystore), evaporation of wet canopy (evapstore), soil evaporation (soilevap), and modelled canopy transpiration (et) (all in $\mathrm{mm}$ ) (variables fully documented in Duursma (2016)) that are converted to $\mathrm{W} \mathrm{m}^{-2}$ for each variable by

$$
Q_{E, e t}=e t \times A_{m m} \times m_{m o l, w} \times \Delta H_{v a p} \times c_{w, k j} \times \text { Time }
$$

where $e t$ is evapotranspiration (mm), $A_{m m}$ is the 2-dimensional tree area in $\mathrm{mm}\left(\mathrm{mm}^{2}\right)$, Time is the time (seconds), $\Delta H_{\text {vap }}$, the enthalpy of evaporation $\left(=42809 \mathrm{~J} \mathrm{~mol}^{-1}\right), c_{w, k j}$, the conversion to watts $(=1 \mathrm{~W} / 1000 \mathrm{KJ} / \mathrm{sec})$, and $m_{m o l, w}$, the molar mass of water $\left(=18.0152 \mathrm{~g} \mathrm{~mol}^{-1}\right)$. The conversion is performed three more times for the remaining variables.

These values are combined to calculate the total $Q_{E, v e g}$ for a grid square in

$$
Q_{E}=Q_{E, \text { et }}+Q_{E, \text { soil }}+Q_{E, \text { canopy }}+Q_{E, \text { evap }}
$$

where each $Q_{E}$ value was previously converted in Equation (2). For large trees (extending beyond the edges of the grid square), the $Q_{E}$ for the entire tree will be applied to grid square where the trunk is located.

With these additions, VTUF-3D is now able to account for $Q_{E}$ in energy balance partitioning, and thus determine the influence of water and vegetation evapotranspiration on temperature predictions in urban canyons.

\subsubsection{Sensible heat and ground storage fluxes}

Convection in TUF-3D (and thus in VTUF-3D) is implemented as an adaptation of the facet-averaged approach of Masson (2000). Full details of calculations are described in Krayenhoff and Voogt (2007). Horizontal advective exchanges are not considered, which is considered to be a reasonable approach given the well-mixed nature of canopy layer air (Krayenhoff and Voogt, 2007). A more accurate but computationally intensive approach could be undertaken using a computational fluid dynamics (CFD) method. However, forcing by the convection between facets is likely less important than the forcing of surface temperatures through the shaded and unshaded radiation distribution and its interactions of surface material properties (Krayenhoff and Voogt, 2007). There is the possibility that the addition of vegetation to the model will increase the importance of interactions between neighbouring surfaces of varying temperatures and moistures. However, as will be seen in the model evaluation process (Section 3), this simplified approach still delivers suitably accurate results without justifying more computationally intensive methods.

Using this convective scheme for sensible heat fluxes $\left(Q_{H}\right)$, vegetation is accounted for differently by modifying the TUF-3D $Q_{H}$ calculations for grid squares with vegetation, using the $T_{s f c, v e g}$ of the vegetation instead of the TUF$3 \mathrm{D} T_{s f c}$ value in Equation (4)

$$
Q_{H, v e g}=h_{i}\left(T_{s f c, v e g}-T_{c a n}\right)
$$

where $h_{i}$ is a calculated heat transfer coefficient $\left(\mathrm{W} \mathrm{m}^{-2} \mathrm{~K}^{-1}\right.$ ) (using Mascart et al. (1995) and the effective wind speed). 
Ground storage flux $\left(Q_{G}\right)$ calculations of vegetated grid squares are modified from the TUF-3D method for nonvegetated grid squares, and are calculated as a residual of the energy balance equation (where $Q_{G}=Q^{*}-Q_{H}-Q_{E}$ ). Thus $Q_{G, v e g}$ fluxes for grid squares containing vegetation are calculated as

$$
Q_{G, v e g}=Q_{v e g}^{*}-Q_{H, v e g}-Q_{E, v e g}
$$

\subsection{Mean radiant temperature and Universal Thermal Climate Index calculations}

VTUF-3D provides output of incoming and outgoing shortwave and longwave radiation and $T_{s f c}$ for each facet (surface) at each timestep. Air temperature for the canyon, $T_{c a n}$, is also provided for each timestep. Using these and values of vapour pressure from the forcing data and wind speed at street level, the values for mean radiant temperature $\left(T_{m r t}\right)$ and the human thermal comfort index UTCI are calculated for each surface. User defined options in the model are available to either calculate $L \downarrow$, using the clear sky formula of Prata (1996), or using forcing values. Based on this, different options will be used to calculate the following equations.

Calculations of $T_{m r t}\left({ }^{\circ} \mathrm{C}\right)$ uses a two step procedure. First, globe temperature $\left(T_{g}\right)$ is calculated by an iterative relaxation solution, using a formulation of Liljegren et al. (2008) in

$$
\begin{aligned}
A \epsilon_{g} \sigma T_{g}^{4} & =\frac{A}{2} \epsilon_{g} \sigma\left(\epsilon_{a} T_{a}^{4}+\epsilon_{s f c} T_{s f c}^{4}\right) \\
& +\frac{A}{2}\left(1-\alpha_{g}\right)\left(1-f_{d i r}\right) S \\
& +\frac{A}{4}\left(1-\alpha_{g}\right) f_{d i r} S / \cos (\theta) \\
& +\frac{A}{2}\left(1-\alpha_{g}\right) \alpha_{s f c} S \\
& -A h\left(T_{g}-T_{a}\right)
\end{aligned}
$$

where $A$, is the surface area of a sphere with diameter D of value $0.15 \mathrm{~m}, \epsilon_{a}$, the longwave emissivity of the atmosphere, $\epsilon_{s f c}$, the longwave emissivity of the surface, $\epsilon_{g}$, the globe emissivity (of value 0.95 ), $h$, the convective heat transfer coefficient $\left(\mathrm{W} \mathrm{m}^{-2} \mathrm{~K}^{-1}\right.$ ) (see Equation (7)), $T_{a}$, the dry bulb air temperature (K) (using $T_{c a n}$ ), $T_{s f c}$, the surface temperature $(\mathrm{K}), \mathrm{S}$, the horizontal solar irradiance $\left(\mathrm{W} \mathrm{m}^{-2}\right)$ calculated from the total of absorbed and reflected shortwave, $\theta$, the solar zenith angle, $\alpha_{s f c}$, the surface albedo (of value 0.15 ), $\alpha_{g}$, the globe albedo (of value 0.05 ), and $f_{\text {dir }}$, the fraction of the total horizontal solar irradiance, $S$, due to the direct beam of the sun.

The convective heat transfer coefficient, $h$, as used in Equation (6), is calculated using

$$
N u=2.0+0.6 \operatorname{Re}^{1 / 2} \operatorname{Pr}^{1 / 3} ; \quad h=k / D N u
$$

where $N u$ is the Nusselt number (-), Re, the Reynolds number (-), Pr, the Prandtl number (-), and $k$, the thermal conductivity of the fluid (i.e. air) $\left(\mathrm{W} \mathrm{m}^{-1} \mathrm{~K}^{-1}\right)$ (Liljegren et al., 2008).

Depending on user defined scenario model configuration settings, a number of terms in Equation (6) can use internally calculated values. $\sigma\left(\epsilon_{a} T_{a}^{4}+\epsilon_{s f c} T_{s f c}^{4}\right)$ can be replaced with $L \downarrow+L \uparrow$, the result of reflections of $L \downarrow_{i, s k y}$. $\left(1-f_{\text {dir }}\right) S$ can be replaced with $K \downarrow_{d i f}$, and $f_{\text {dir }} S / \cos (\theta)$ with $K \downarrow_{\text {dir }}$. Also, for vegetated grid squares, the terms for $L \downarrow$ and $L \uparrow$ can be replaced with calculations of $L \downarrow$ and $L \uparrow$ from $\epsilon \sigma T^{4}$ where $T_{s, 1}$, soil surface temperature (K), is used as the temperature term for the $L \uparrow$ calculation while leaf temperature is used for $L \downarrow$.

Using $T_{g}$, calculated in Equation (6), the second step in calculating $T_{m r t}$ proceeds in a formulation of Kántor and Unger (2011)

$$
T_{m r t}=\left(\left(T_{g}+273.15\right)^{4}+\frac{1.1 \times 10^{8} w s_{c m}^{0.6}}{\epsilon_{g} D^{0.4}} \times\left(T_{g}-T_{a}\right)\right)^{0.25}-273.15
$$

where $w s_{c m}$ is the wind speed $\left(\mathrm{cm} \mathrm{s}^{-1}\right)$.

Finally, the Universal Thermal Climate Index (UTCI) $\left({ }^{\circ} \mathrm{C}\right)$ for each surface is calculated using the Bröde (2009) UTCI formula, generating UTCI values for each surface, allowing human thermal comfort to be examined in detail across a modelled domain. The calculation uses modelled outputs of air temperature, wind speed (using model 
calculated wind speed at canyon level), relative humidity (from the forcing data), and $T_{m r t}$ (calculated above). VTUF3D does not currently calculate a canopy level relative humidity. This is a current limitation and a future enhancement for the model. But as will be shown in the evaluation of VTUF-3D focusing on urban canopy layer air temperature, $T_{m r t}$, and UTCI predictions (Section 3.2) and in the energy flux evaluation (Section 3.1), the model still performs well despite this limitation.

\subsection{New VTUF-3D shading logic integrating vegetation shading}

In order to understand the changes made to create VTUF-3D, an brief overview of the original TUF-3D logic is necessary. Two dimensional $(\mathrm{x}, \mathrm{y})$ locations of building locations are configured along with their heights. TUF-3D uses forcing data of temperature, humidity, incoming radiation levels, and wind speed and direction from a location at specified $\mathrm{z}$ height (above the canopy). Wind is used in roughness calculations but not used to resolve movements around the buildings (as a CFD based model would). This simplification is a design decision trade-off to reduce the complexity of the model and the intensity of computations, while still producing robust enough results.

The domain initialisation ray tracing routines of TUF-3D have not been modified. In these (Figure 3a), unnecessary interactions are determined during the model initialisation process by finding which surfaces are visible to each other and which pairs of surfaces are fully obstructed by other surfaces and need not be considered in determining radiation exchanges. Then, as the model runs the main simulation, at each timestep, TUF-3D runs a shading routine (Figure 3b). In it, the model iterates through each surface in the domain (roads and building walls and roofs), tracing rays four times from each quarter of the surface towards the sun to determine that surface's level of illumination, yielding results of $0,25,50,75$, and $100 \%$ illuminated. By using these sunlit levels, each surface can be allocated the appropriate amount of incoming radiation during the energy balance process.

\subsubsection{Integrating vegetation shading and modified ray tracing logic in VTUF-3D}

After model improvements to VTUF-3D were made, a similar parallel logic was created to represent the vegetation in the domain. These vegetation elements are ignored in the initial ray-tracing (Figure 3a). This initial ray tracing is performed to optimise the modelling, to exclude any two surfaces which will never be visible to each other. However, depending on the density of the vegetation, the pathway between two surfaces might not be completely obscured by vegetation, so these cases will have to be evaluated during the simulation run.

At each timestep during the simulation, VTUF-3D now runs a modified shading routine (Figure 3c). During the model iteration through each surface in the domain, upward ray-traces towards the sun are performed as described previously (the TUF-3D default method). However, each step of the ray trace checks to see if vegetation has been encountered, and if encountered sets a flag to indicate further processing will be needed. Then the ray trace continues and concludes when it either passes out of the domain or is blocked by a building. If no vegetation is encountered, radiation exchanges between surfaces along the ray default to the original TUF-3D method. Otherwise additional processing needs to be done to account for the radiation exchanges affected by vegetation.

To resolve the sunlit factor for surfaces that encountered vegetation during the ray trace, ray tracing is performed in reverse (downward) for those beams (Figure 3d). For surfaces 5 and 6 in Figure 3d, ray tracing is done from the top of the domain back along the radiation path. When the ray encounters vegetation (surfaces 5 and 6), VTUF-3D looks up the tree associated with the ground surface below and loads the offline calculations of the amount of radiation reflected, absorbed, and transmitted through the vegetation. The ray tracing continues, allocating the remaining radiation either to further intercepting vegetation or ultimately to the final ground or building surface.

Each item of vegetation in the domain is modelled offline and these data are made available for the main simulation run. In order to account for the effects of inter-tree shading or shading by buildings during the main simulation run, these offline vegetation calculations are run twice using varied amounts of incoming shortwave. The first variation uses $100 \%$ incoming solar radiation to account for when the vegetation is in full sun. The second variation uses only the diffuse component of the incoming solar radiation for when the vegetation is shaded by obstructions. The proper variation for each item of vegetation is chosen programmatically (based on its current sunlit percentage) during the model run. As the illumination levels vary in each location in an urban canyon across the diurnal cycle, these variations allow the differing vegetation responses (varying levels of photosynthesis due to lower levels of PAR, changes in surface temperatures, and varying vegetation evapotranspiration due to differences in stomatal conductance and vapour pressure deficits) to be captured. However, these variations will not be able to exactly capture every variation, such 


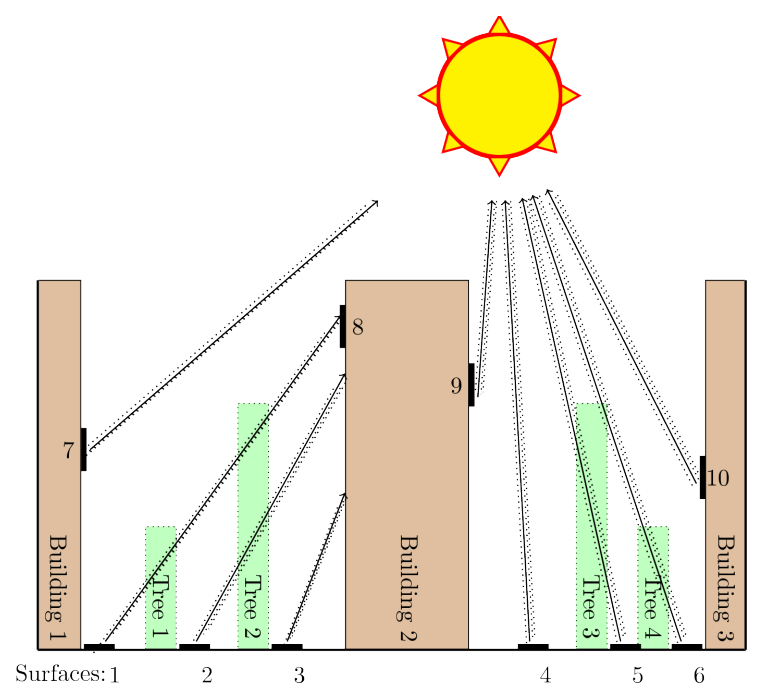

(a) Initial view angles ray tracing.

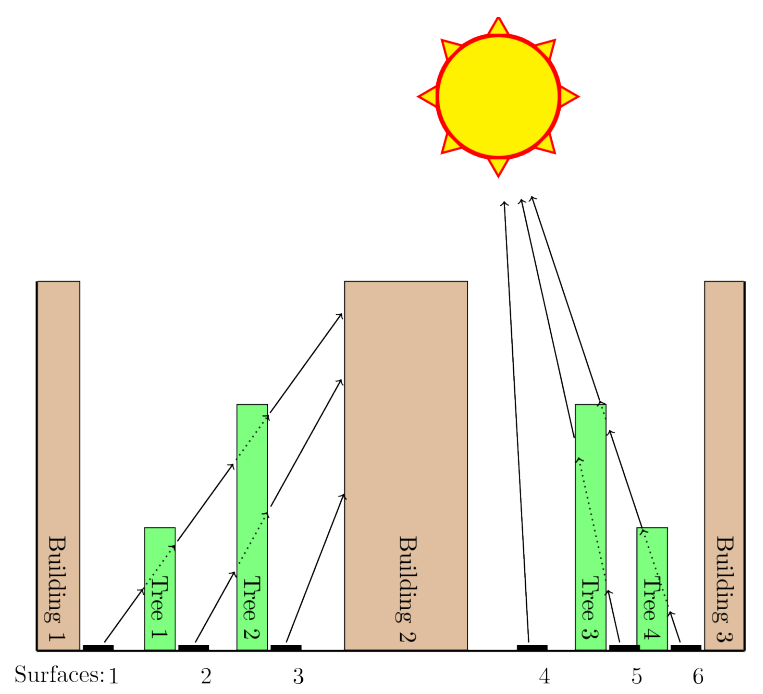

(c) VTUF-3D modified shading.

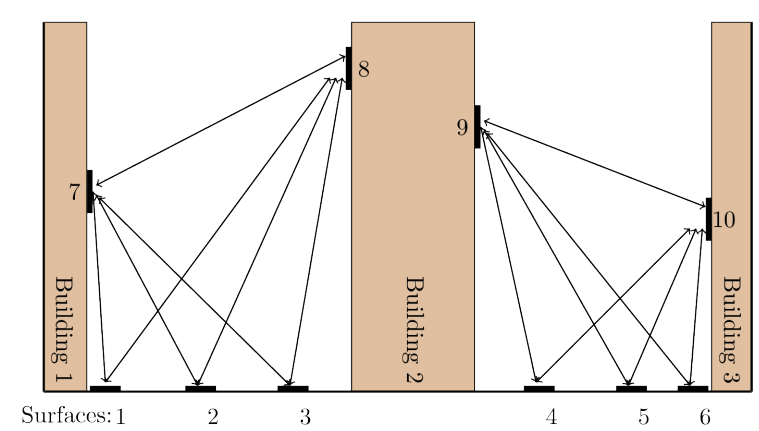

(b) TUF-3D unmodified shading.

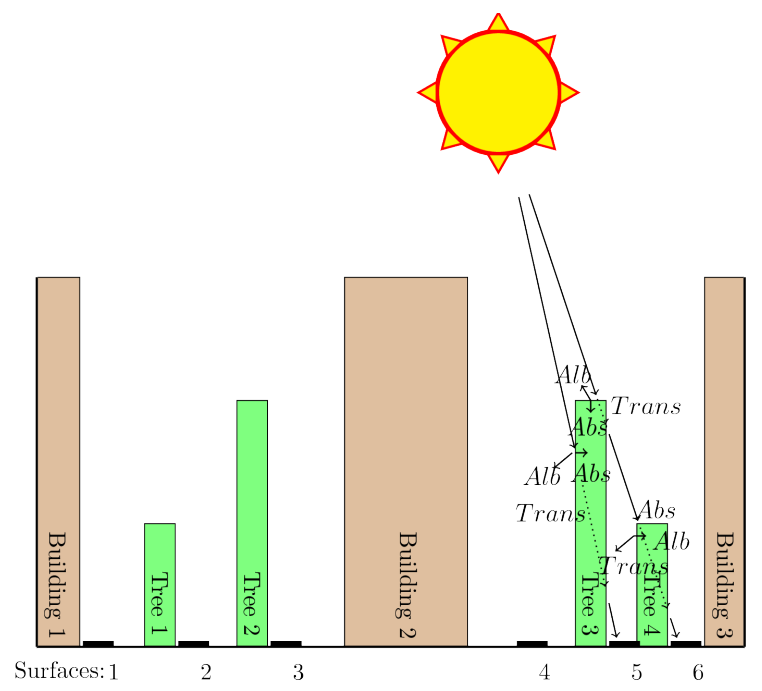

(d) VTUF-3D reverse ray tracing.

Figure 3: (a) Initial view angles ray tracing, run during model initialisation to determine which surfaces are visible to each other. Trees depicted with dashed borders to emphasise they are present in the domain but are not considered at this point in the simulation. (b) TUF-3D unmodified shading logic in which each surface performs four ray traces (from each surface quarter) upwards towards the sun and determines sunlit percentage based on how many rays leave the domain without meeting an obstruction. Vegetation modelling is not possible in TUF-3D, so is not depicted. (c) VTUF-3D modified shading, timestep ray tracing, using the same process as the unmodified logic but setting a flag for any ray that encounters vegetation. (d) VTUF-3D modified shading, downward ray tracing. For any rays that encounter vegetation during upward ray tracing, additional ray traces are performed in reverse (downward) to allocate radiation to intervening encountered surfaces. 
as a reduction in diffuse shortwave due to a nearby building. Examples of the forcing data required for these offline variations are described in the Pr04Val evaluation set-up (Section 3.1.2).

\section{Model evaluation}

\subsection{Evaluation of modelled energy fluxes}

Evaluations of VTUF-3D need to be performed to ensure that this new model is making accurate predictions. As an energy balance model, modelled output comparisons to observations of energy fluxes and temperatures are considered fundamental evaluations (Masson, 2002). With the addition of vegetation modelling, it is important that those aspects are also properly evaluated.

\subsubsection{Evaluation data}

An evaluation was performed based on flux tower observations recorded in the suburb of Preston, in northern Melbourne, Australia (Coutts et al., 2007). Preston is a homogeneous, low to medium density area and characterised as LCZ6B (open low-rise) (Stewart and Oke, 2012). A 40 metre flux tower recorded observations during 2003 and 2004 (Coutts et al., 2007), providing observed values of $Q^{*}, Q_{H}, Q_{E}$, air temperature, humidity, wind speed and direction. $Q_{G}$ was calculated as a residual of the surface energy balance. Estimates of the anthropogenic heat flux $\left(Q_{F}\right)$ were made using an inventory approach, though $Q_{F}$ is included implicitly in the observations and contributes to the observed sensible heat fluxes. The use of this data set allows an evaluation of surface energy balances against modelled predictions. This data set was also used as the forcing and comparison data set for Phase 2 and 4 of the International Urban Energy Balance Models Comparison Project (Grimmond et al., 2011; Best and Grimmond, 2012). Phase 2 of this comparison project evaluated the performance of 32 urban land surface modelling schemes, forced by and compared to these observations, using a consistent methodology. Phase 4 re-evaluated many of these modelling schemes for their performance across a variety of seasonal cycles.

\subsubsection{Evaluation set up}

The modelled domain (100x100m with a 5m grid resolution) was an area of interest (AOI), chosen to be representative of the overall land cover influencing the fluxes at the tower (Figure 4). Aerial imagery from 2015 (Google Maps, 2015) was used as an initial basis for the modelling domain. The measurement height for the observations ensured that the measured fluxes well represented the local scale (approximately 1000 meters) of the area (Coutts et al., 2007). Additionally, the site selection ensured a homogeneous nature of the overall flux coverage area (Schmid, 1994). Because of this, the micro-scale modelled domain is representative of the fluxes observed at a local scale. This is confirmed by the land surface classification of the site. Coutts et al. (2007) undertook a land surface classification using aerial imagery (from 2002) within a $500 \mathrm{~m}$ radius of the observation tower to support interpretation of the 200304 flux data. The selected AOI (Figure 4) is in good agreement with the $500 \mathrm{~m}$ radius classification of Coutts et al. (2007) with respect to the pervious/impervious fractions. Breakdowns of both classifications, and the $100 \mathrm{~m} \times 100 \mathrm{~m}$ domain used here are shown in Table 1. Overall, the modelled domain selection is very similar to the broader area and is representative of the local scale allowing an appropriate comparison between the observed and modelled results. In addition to the land cover fractions, other properties of the observation site are listed in Table 2.

Table 1: Preston land cover classification of a 500m radius from the observation tower from Coutts et al. (2007) and Nury (2015), and the classification of the model domain area of interest (AOI) (all in percentages).

\begin{tabular}{|c|c|c|c|c|c|c|c|}
\hline Source & Blg. & Imp. & Tree & Grass & Water & Tot. Imp. & Tot. Per. \\
\hline 500m radius & & & & & & & \\
\hline Coutts et al. (2007) & 44.5 & 17.5 & 22.5 & 15.0 & 0.5 & 62.0 & 38.0 \\
\hline Nury (2015) & 32.0 & 34.5 & 10.1 & 23.4 & 0 & 66.5 & 33.5 \\
\hline & & & & & & & \\
\hline AOI (100x100m) & 45.2 & 19.3 & 16.0 & 19.5 & 0 & 64.5 & 35.5 \\
\hline
\end{tabular}

The 2015 imagery used here for the model domain was 13 years after the 2002 imagery used in Coutts et al. (2007). In a remote sensing study by Nury (2015) examining urban greenery and heat mitigation, a land cover classification 

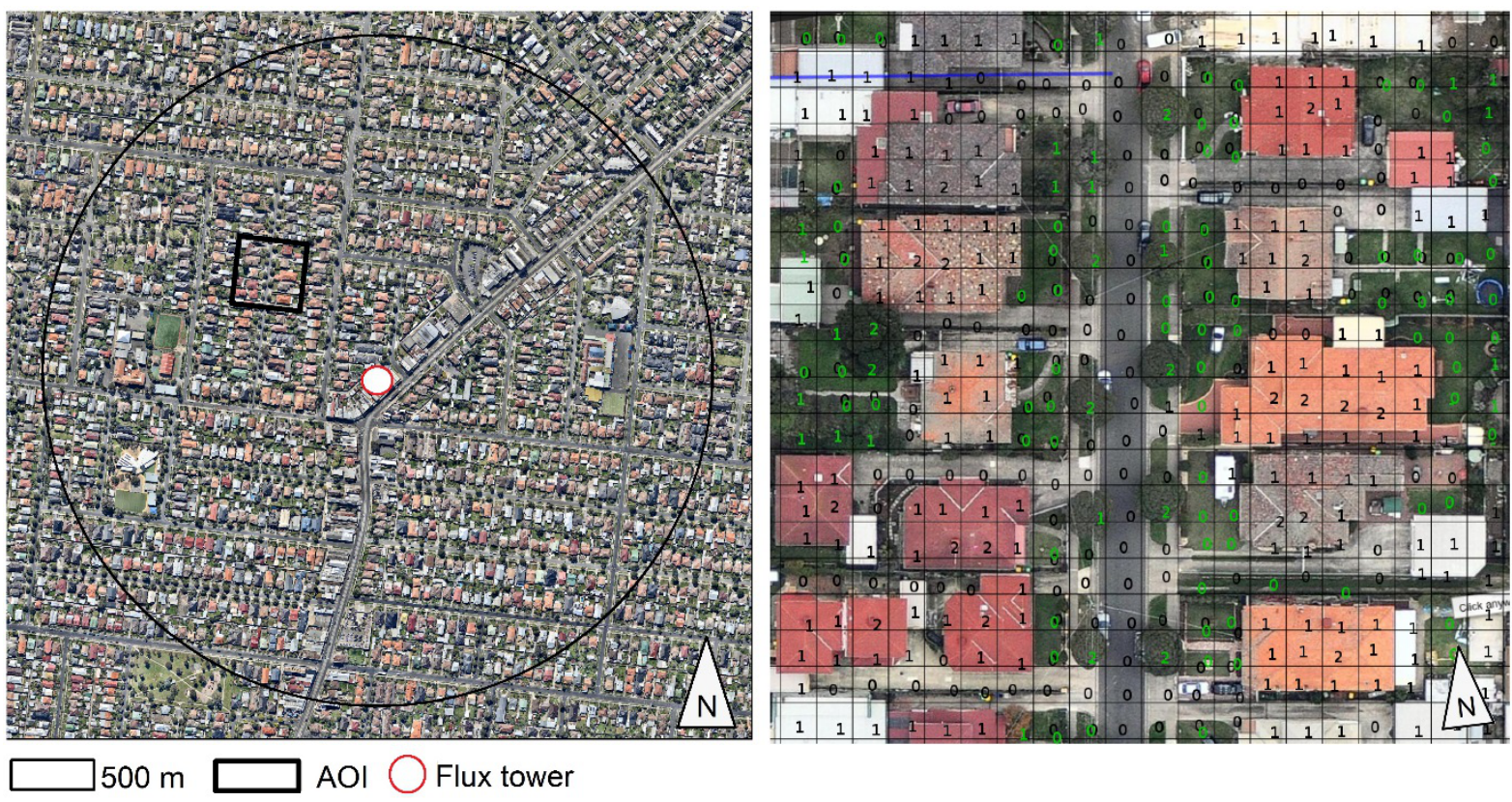

Figure 4: Observed Preston suburb showing 500m effective radius of flux tower observations. Black box annotates model domain area of interest (AOI). Adapted from Google Maps (2015). / Digitisation of AOI, Preston suburban street, Oakhill Ave. Building heights in black, vegetation heights in green (in 5m units). Adapted from Nearmap (2015).

Table 2: Preston evaluation site properties (Coutts et al., 2007).

\begin{tabular}{|l|l|}
\hline Property & Value(s) \\
\hline$\alpha$, albedo & 0.15 \\
\hline$z_{m}$, instrument height $(\mathrm{m})$ & 40 \\
\hline$z_{0}$, roughness length $(\mathrm{m})$ & 0.4 \\
\hline$z_{h}$, maximum height of roughness elements $(\mathrm{m})$ & 12 \\
\hline$z_{b}$, mean building height $(\mathrm{m})$ & 6.4 \\
\hline$H: W$, mean height to width ratio & 0.42 \\
\hline$W: P$, mean wall-to-plan ratio & 0.4 \\
\hline
\end{tabular}


of the Darebin Council area $\left(55.6 \mathrm{~km}^{2}\right.$ ) (which includes Preston) was performed using aerial imagery from 2009 and LIDAR data from 2008. This land surface classification was much improved in terms of accuracy (due to higher quality and higher resolution imagery) than that of Coutts et al. (2007) and provided a more recent set of land surface data (Table 1). Some differences in the classification were seen, with the Nury (2015) classification showing a lower building fraction and a higher impervious surfaces. Further, some reduction in vegetation cover is seen between the Coutts et al. (2007) classification and the Nury (2015) classification. This introduces a small amount of uncertainty in the exact make-up of the modelling domain and could explain some of the low predictions of $\mathrm{Q}_{E}$ seen later in this evaluation. While the Nury (2015) dataset was generated from different resolution imagery and from a later time period, it does show very good agreement with the total impervious/pervious fraction of the 500m classification.

Model parameters were set to the values given in Table 3 and domain parameter values in Table 1. Most of these values are TUF-3D default values, from Krayenhoff and Voogt (2007). The modelled domain is a digitisation of the AOI, Oakhill Ave. in Preston (Figure 4) with building locations and heights as shown in Figure 5.

Table 3: Preston evaluation scenario model parameters.

\begin{tabular}{|l|l|l|}
\hline Parameter & Value(s) & Source \\
\hline Albedo (roof, street, wall) & $0.15,0.10,0.30$ & Krayenhoff and Voogt (2007) \\
\hline Emissivity (roof, street, wall) & $0.92,0.92,0.88$ & Krayenhoff and Voogt (2007) \\
\hline Forcing data height (m) & 40 & Coutts et al. (2007) \\
\hline Mean height of buildings (m) & 5.61 & Calculated from domain \\
\hline Mean height of trees (m) & 5.7 & Calculated from domain \\
\hline Initial $T_{\text {sfc }}$ (roof, street, wall) $\left({ }^{\circ} \mathrm{C}\right)$ & $18.0,23.0,22.0$ & Krayenhoff and Voogt (2007) \\
\hline $\begin{array}{l}\text { Constant building internal air temperature (base of roofs } \\
\text { and walls) }\left({ }^{\circ} \mathrm{C}\right)\end{array}$ & $22.0,20.0$ & Krayenhoff and Voogt (2007) \\
\hline Constant deep-ground temperature $\left({ }^{\circ} \mathrm{C}\right)$ & 19.0 & Krayenhoff and Voogt (2007) \\
\hline Constant building internal floor temperature $\left({ }^{\circ} \mathrm{C}\right)$ & 15.0 & Krayenhoff and Voogt $(2007)$ \\
\hline
\end{tabular}

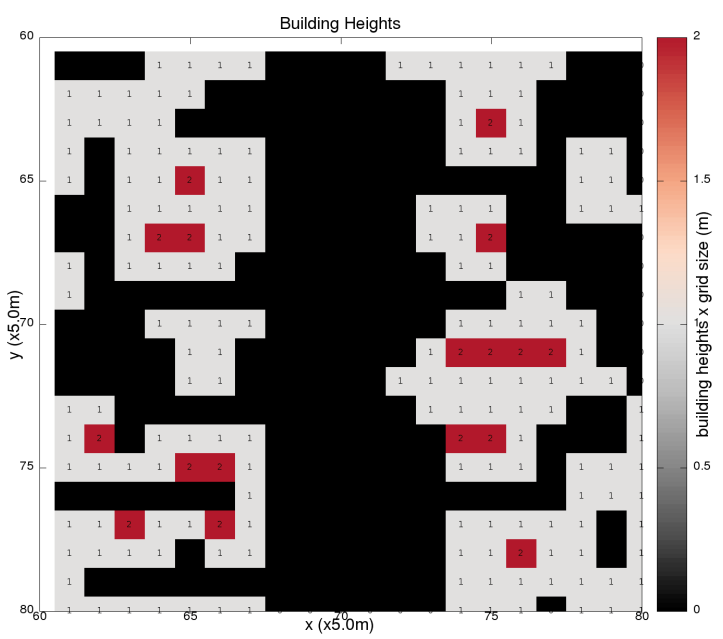

Figure 5: Preston evaluation domain configured building heights $(0,5,10 \mathrm{~m})$ and locations for modelling scenario Pr04Val.

Vegetation (trees, shrubs, and ground cover) is added to VTUF-3D by populating physiological and physical parameter values (using observed or literature values) in configuration files. This means any species or type of vegetation can be included in VTUF-3D. Two tree types were employed in this evaluation, namely Olea europaea (Olive) and Lophostemon Confertus (Queensland brushbox), as well as turf grass, Festuca arundinacea (Tall Fescue). The detailed parameterisations for these vegetation types are shown in Appendix A. A mix of 25\%/75\% Olea europaea and Lophostemon Confertus) trees were used in the model. Identifying and parametrising every tree species in the domain 
can be time consuming, so our parametrisations were limited here to these species. The species mix was chosen to best account for density of canopy cover in the aerial imagery but given this limitation, will not completely reflect the observed species mix and might create some modelling errors from the observed fluxes. However, the two available species are representative of commonly planted trees in Melbourne. A street tree inventory by Frank et al. (2006) finds that Lophostemon Confertus, a native evergreen, is the most common street tree, representing $6.9 \%$ of street trees in Melbourne. Olive trees are considered suitable for Melbourne's climate conditions (drought tolerant evergreen) and a recommended species for council street tree planting (City of Port Phillip, 2010).

The evaluation simulation (which is named Pr04Val) was run for 30 days, from 10 February 2004 to 10 March 2004, forced by the observations from Coutts et al. (2007) for those days. Meteorological forcing included $K \downarrow, L \downarrow$, air temperature, wind speed, wind direction, and air pressure at a height of $40 \mathrm{~m}$. Forcing data for the vegetation components use shortwave values of mean global and mean diffuse observations taken from one minute solar observations (station 086282, Melbourne Airport) (Bureau of Meteorology, 2016b). For full radiation vegetation runs, the mean global irradiance was used while for diffuse runs, the mean diffuse irradiance was used. In addition, the MAESPA FBEAM variable (fraction of incident PAR which is direct-beam) is set to 0.0 in the forcing data for diffuse runs.

The evaluation period contained a range of conditions. The period especially features a number of hot days (over $30^{\circ} \mathrm{C}$ ). As one of the major applications of VTUF-3D will examining the potential for moderating urban heat through urban vegetation, evaluation over a period containing hot days is important. The observation period also contains a number of days with precipitation. In the current VTUF-3D design, precipitation will only be received in grid squares that contain vegetation and pervious surfaces. The expected impact of this is that predictions of $Q_{E}$ will be understated for days that contain precipitation. Accounting for rainfall on impervious surfaces is a current limitation of VTUF3D (to be addressed in later versions of VTUF-3D) and caution should be used in modelling periods which contain significant rainfall. For the intended primary use of VTUF-3D, examining temperature moderation during the hottest periods of the year (often containing little rainfall), rainfall limitations should be less of an issue. Also, in most urban areas, precipitation on impervious surfaces will be rapidly removed as stormwater.

\subsubsection{Evaluation approach}

The evaluation scenario (Pr04Val) compares the modelled results for the 30 day run with the observed fluxes $\left(Q^{*}, Q_{H}, Q_{G}\right.$, and $Q_{E}$ ) for the domain that aligns well with the land surface classification for the wider local scale area (Table 1). Comparisons with the observations were performed using the Willmott (1981) $d$ index of agreement as well as calculating mean absolute error (MAE), mean bias error (MBE), and root-mean-square error (RMSE) statistics. In addition, the VTUF-3D model was run with a 'no vegetation scenario', undertaken to demonstrate the significant improvement of model performance with vegetation included. This scenario (named Pr04NoVeg), represents an unimproved TUF-3D without vegetation modelling capability, as the lack of vegetation will not trigger any of the new logic and improvements added to the model. Finally, as the observations used in this evaluation are the same as in Phase 4 of the Intercomparison project (Best and Grimmond, 2012), using the Coutts et al. (2007) Preston dataset, the performance of the VTUF-3D model can also be placed within the intercomparison evaluation of urban land surface modelling schemes. These schemes include the 24 surface energy balance models with sufficient resolution to resolve features of and interactions in urban areas. The Intercomparison Phase 4 provides MBE and RMSE statistics for fluxes $Q^{*}, Q_{H}, Q_{G}$, and $Q_{E}$, grouped by three classifications of urban models. These three categories are of models that do not consider vegetation, those that model vegetation using tiles, and models that integrate vegetation into the urban area (referred to as classifications IntercomparisonNoVeg, IntercomparisonTiled, and IntercomparisonIntegrated, described in Table 4). The tiled approach calculates vegetation and urban surfaces separately and the two surface types only interact through their combined influence on variables such as temperatures. As the most complex scheme, the integrated approach allows interactions and influences between each of the two elements within a timestep. VTUF-3D aligns most closely with a tiled vegetation approach. Table 4 summarises all the different scenarios compared during this study's evaluation process.

\subsubsection{Evaluation results}

Figure 6 presents the mean diurnal pattern for each component of the surface energy balance $\left(Q^{*}, Q_{H}, Q_{G}\right.$, and $Q_{E}$ ) over the 30 day evaluation period. The observed individual fluxes were aggregated into hourly averages over the 
Table 4: VTUF-3D evaluation scenario names and descriptions. Also, source of the three Intercomparison project result sets used to determine VTUF-3D's relative performance compared to other urban land surface models.

\begin{tabular}{|l|l|}
\hline Scenario name & Description \\
\hline Pr04NoVeg & Baseline no-vegetation simulation with unimproved TUF-3D \\
\hline Pr04Val & Preston 2004 evaluation scenario \\
\hline IntercomparisonNoVeg & $\begin{array}{l}\text { Best and Grimmond (2012) intercomparison performance mean of urban models } \\
\text { that do not model vegetation }\end{array}$ \\
\hline IntercomparisonTiled & $\begin{array}{l}\text { Best and Grimmond (2012) intercomparison performance mean of urban models } \\
\text { that tile vegetation }\end{array}$ \\
\hline IntercomparisonIntegrated & $\begin{array}{l}\text { Best and Grimmond (2012) intercomparison performance mean of urban models } \\
\text { that integrate vegetation }\end{array}$ \\
\hline
\end{tabular}

30 days and compared with the hourly averaged model output. VTUF-3D was able to reproduce the important energy dynamics of this area as seen in the component fluxes. In the observations, the $Q_{H}$ and $Q_{G}$ fluxes dominate the urban

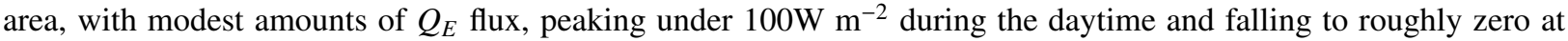
night-time. This pattern was also seen in the model, with $Q_{H}$ and $Q_{G}$ dominating the surface energy balance, while $Q_{E}$ was relatively small. VTUF-3D captures closely both the magnitude and diurnal cycle of $Q_{H}$, with a slight underprediction during the morning and a slight over-prediction during the late mornings. VTUF-3D also captures closely the cycles of $Q^{*}$. The very small divergence between the predicted and observed values of $Q^{*}$ can be explained through the dual sources of values for $K \downarrow$ in the forcing data. Observations from Preston and the Melbourne Airport, located approximately $20 \mathrm{~km}$ apart, provide slightly varied values as a component of the calculated $Q^{*}$ that are then compared to only the Preston observations. $Q_{G}$ shows close agreement except for a slight over-prediction during the mornings, and at mid-day, a slight under-prediction during the afternoon cooling period, and a very slight over-prediction during the evening.
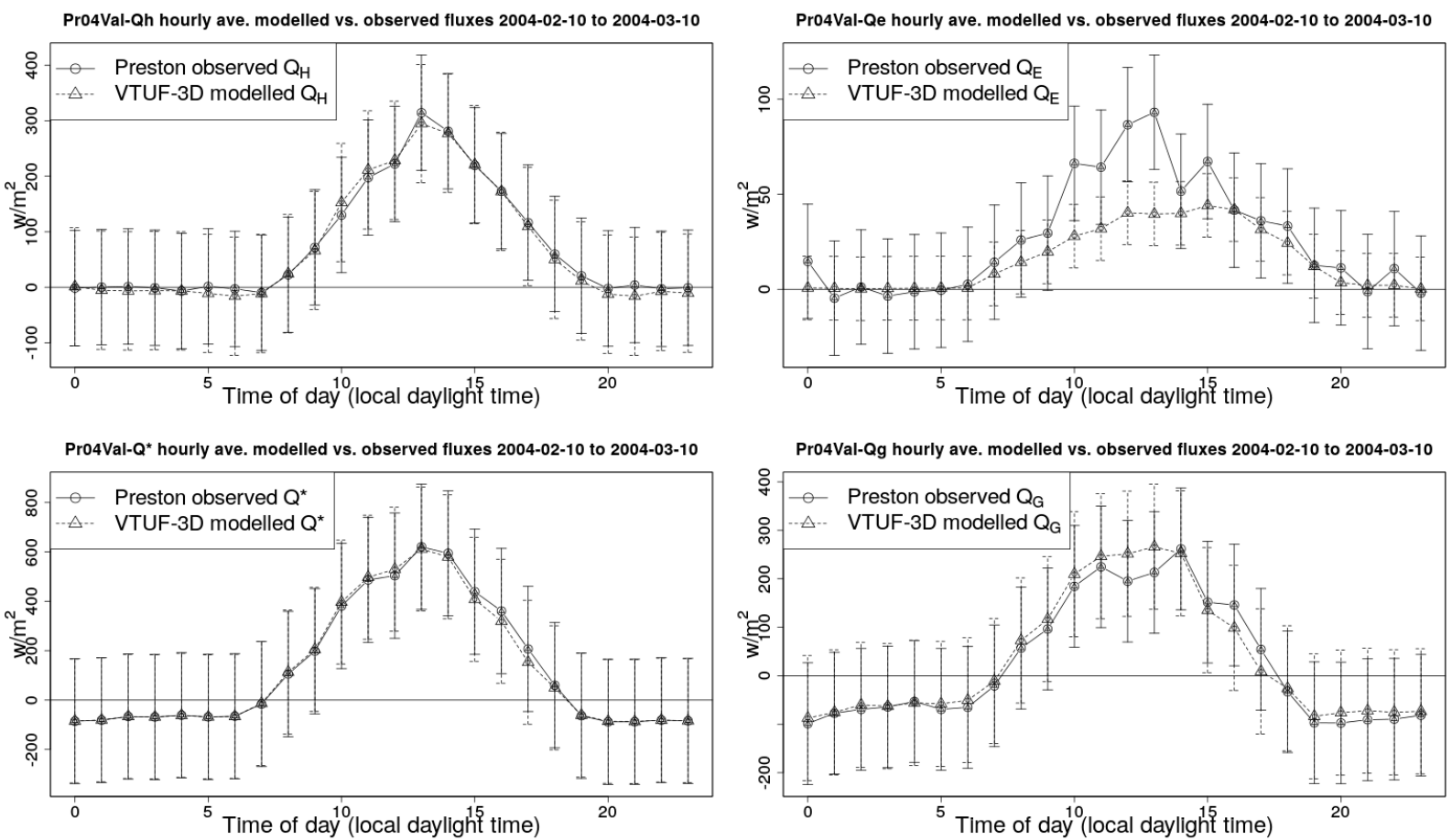

Figure 6: Pr04Val run 30 day hourly average VTUF-3D flux comparisons to Preston flux observations for the period 10 February-10 March 2004, with error bars at standard deviations. 
In a comparison of the 30 day monthly hourly averages, daily observed values of $Q_{H}$ peak at $314 \mathrm{~W} \mathrm{~m}{ }^{-2}$ compared to modelled values of $294 \mathrm{~W} \mathrm{~m}^{-2}$ for the Pr04Val scenario. For the other fluxes, $Q_{E}, Q^{*}$, and $Q_{G}$, peaking observed vs. modelled values are 93 vs. 40, 621 vs. 612, and 213 vs. $266 \mathrm{~W} \mathrm{~m}^{-2}$ respectively. The d, index of agreement (in which 1 indicates perfect agreement and 0 no agreement), for the Pr04Val evaluation (Figure 7) shows d values of 0.964, 0.652, 0.998, and 0.957 for $Q_{H}, Q_{E}, Q^{*}$, and $Q_{G}$ respectively. RMSE $\left(\mathrm{W} \mathrm{m}^{-2}\right)$ values are seen of 40.2, 33.1, 19.0, and 52.5. $\mathrm{MBE}\left(\mathrm{W} \mathrm{m}^{-2}\right)$ values are seen of $-4.0,-9.5,3.0$, and -8.3 .
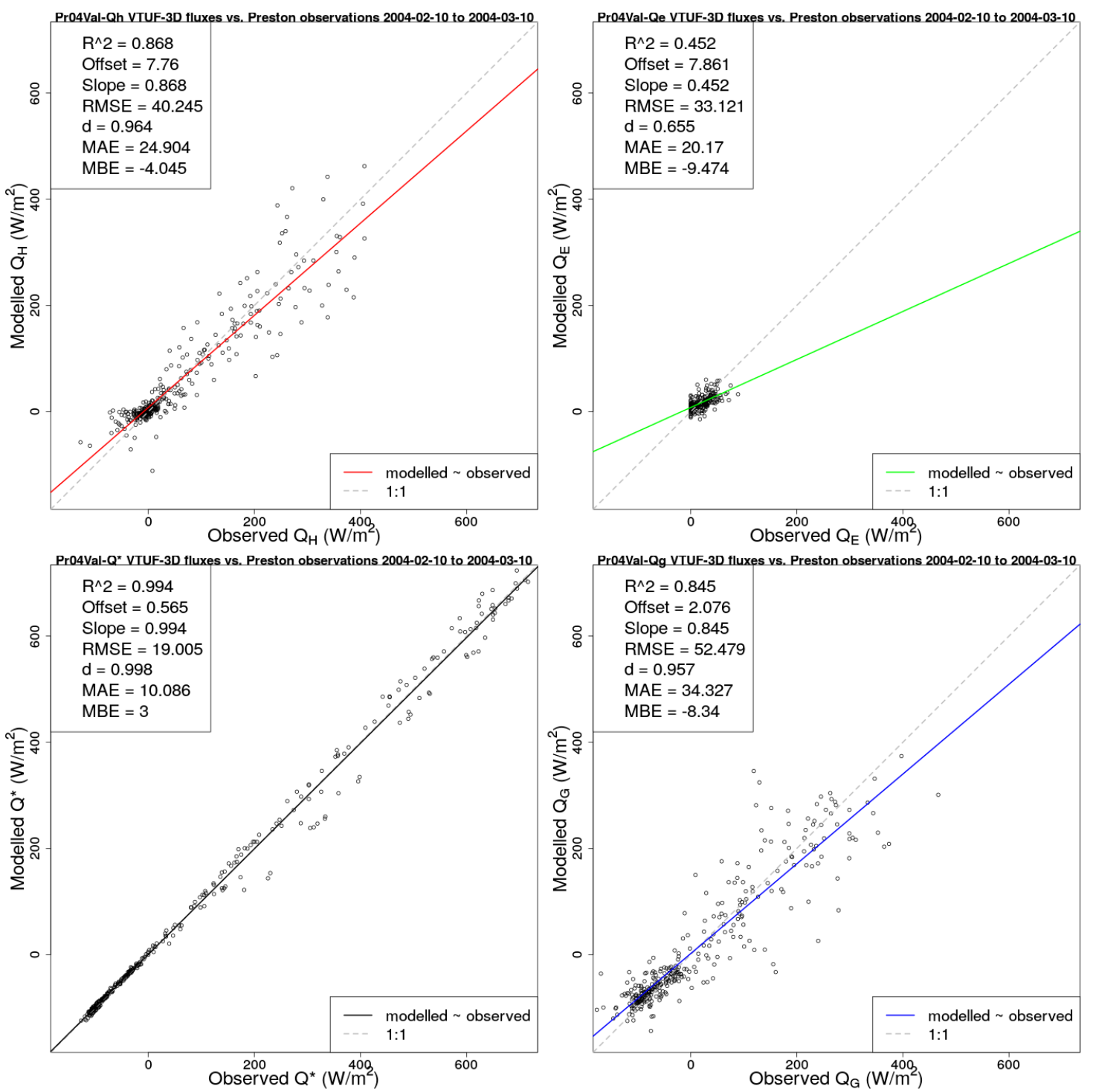

Figure 7: Pr04Val scenario modelled vs. observations for $Q_{H}, Q_{E}, Q^{*}$, and $Q_{G}$ fluxes for the period 10 February-10 March 2004.

Figure 8 presents a 30 day hourly average of both the Pr04Val and Pr04NoVeg scenarios with Pr04Val showing a much closer fit for all fluxes over a diurnal cycle. Figure 9 shows each component of the surface energy balance for the no vegetation scenario (Pr04NoVeg). These values show an improvement over the unimproved VTUF-3D model. The unimproved model yields results of $\mathrm{d}$ of $0.906,0.0,0.989$, and 0.877, RMSE $\left(\mathrm{W} \mathrm{m}^{-2}\right)$ of 87.0, 47.1, 51.6, 75.9, and $\operatorname{MBE}\left(\mathrm{W} \mathrm{m}^{-2}\right)$ of $-6.3,23.8,41.1,11.0$ for $Q_{H}, Q_{E}, Q^{*}$, and $Q_{G}$ respectively. With the unimproved model, $Q_{H}$ is significantly over-predicted during the afternoon and under-predicted in the evenings. Flux $Q_{G}$ is under-predicted during the afternoons. Finally, $Q_{E}$ is not implemented in the model, so cannot be predicted at all. 

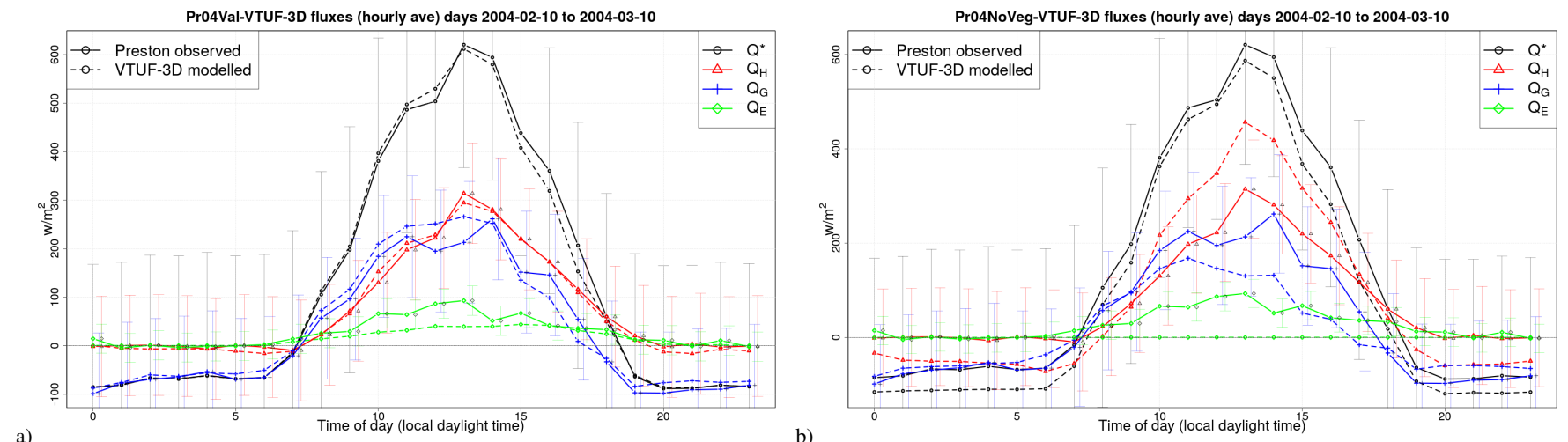

Figure 8: a) Pr04Val and b) Pr04NoVeg scenarios. 30 day hourly average VTUF-3D flux comparisons to Preston flux observations for the period 10 February-10 March 2004, with error bars at observations standard deviations.

As an extension to the TUF-3D model, the addition of vegetation and associated $Q_{E}$ fluxes to VTUF-3D have provided a large improvement to the model. The results of the intercomparison project (Grimmond et al., 2011; Best and Grimmond, 2012) showed that land surface modelling schemes that include vegetation perform better than those that do not. In addition, schemes that integrate vegetation perform better than schemes that use a tiling method and treat the urban canyon and vegetation separately. Another important result from the intercomparison project was that $Q_{E}$ is the least well modelled flux across a range of urban land surface modelling schemes (Grimmond et al., 2010). Even the SUEWS model, which includes vegetation, as well as a very complete urban hydrology, tends to under-estimate $Q_{E}$ fluxes during day-time (Järvi et al., 2011).

Using the RMSE and MBE values for fluxes $Q^{*}, Q_{H}, Q_{G}$ from Phase 4 of the Intercomparison project, the performance of the Pr04NoVeg scenario (as well as the Pr04NoVeg scenario) can be compared with the performance of 24 other urban land surface models. The RMSE and MBE values are taken from Figure 2 of Best and Grimmond (2012), for the Feb/Mar period, corresponding to the period for which the evaluation scenarios were run. A comparison of these Intercomparison MBE and RMSE results vs. modelled results is shown in Table 5. In the Phase 4 comparisons, for all fluxes, models with integrated vegetation schemes had the lowest RMSE values (and Grimmond et al. (2011) found that models without vegetation schemes were among the poorest performers). These were followed by models with tiled vegetation schemes while models without vegetation schemes had the highest values. In comparison, the VTUF-3D Pr04Val scenario had lower RMSE values for all fluxes except $Q_{E}$ than each of the Phase 4 three categories. For $Q_{E}$, the VTUF-3D scenario Pr04Val performed better than the no vegetation group, but with slightly higher errors than the tiled and integrated groups. In terms of absolute differences between RMSE values for the best performing Intercomparison model group, Pr04Val scenario RMSE values differed by $-6,-5,-25$, and $7 \mathrm{~W} \mathrm{~m}{ }^{-2}$ for $Q^{*}, Q_{H}, Q_{G}$, and $Q_{E}$ respectively. In MBE values, VTUF-3D performed better for $Q_{H}$ and $Q_{G}$ in all categories, better than the tiled and integrated groups with $Q^{*}$, and better for $Q_{E}$ in the no vegetation group.

Table 5: RMSE ( $\mathrm{W} \mathrm{m}^{-2}$ ) and MBE $\left(\mathrm{W} \mathrm{m}^{-2}\right.$ ) statistics VTUF-3D vs. Intercomparison (Best and Grimmond, 2012) comparison for Preston evaluation scenarios for 10 February-10 March 2004.

\begin{tabular}{|l|l|l|l|l|l|l|l|l|}
\hline Scenario name & \multicolumn{4}{|c|}{ RMSE } & \multicolumn{4}{c|}{ MBE } \\
& $Q^{*}$ & $Q_{H}$ & $Q_{G}$ & $Q_{E}$ & $Q^{*}$ & $Q_{H}$ & $Q_{G}$ & $Q_{E}$ \\
\hline Pr04Val & 19.0 & 40.2 & 52.5 & 33.1 & 3.0 & -4.0 & -8.3 & -9.5 \\
\hline Pr04NoVeg & 51.6 & 87.0 & 75.9 & 47.1 & 41.1 & -6.3 & 11.0 & 23.8 \\
\hline IntercomparisonNoVeg & 40 & 105 & 85 & 38 & 2 & 45 & -16 & -32 \\
\hline IntercomparisonTiled & 27 & 60 & 77 & 25 & -7 & 13 & -22 & -1 \\
\hline IntercomparisonIntegrated & 25 & 45 & 77 & 26 & -5 & 13 & -18 & -3 \\
\hline
\end{tabular}



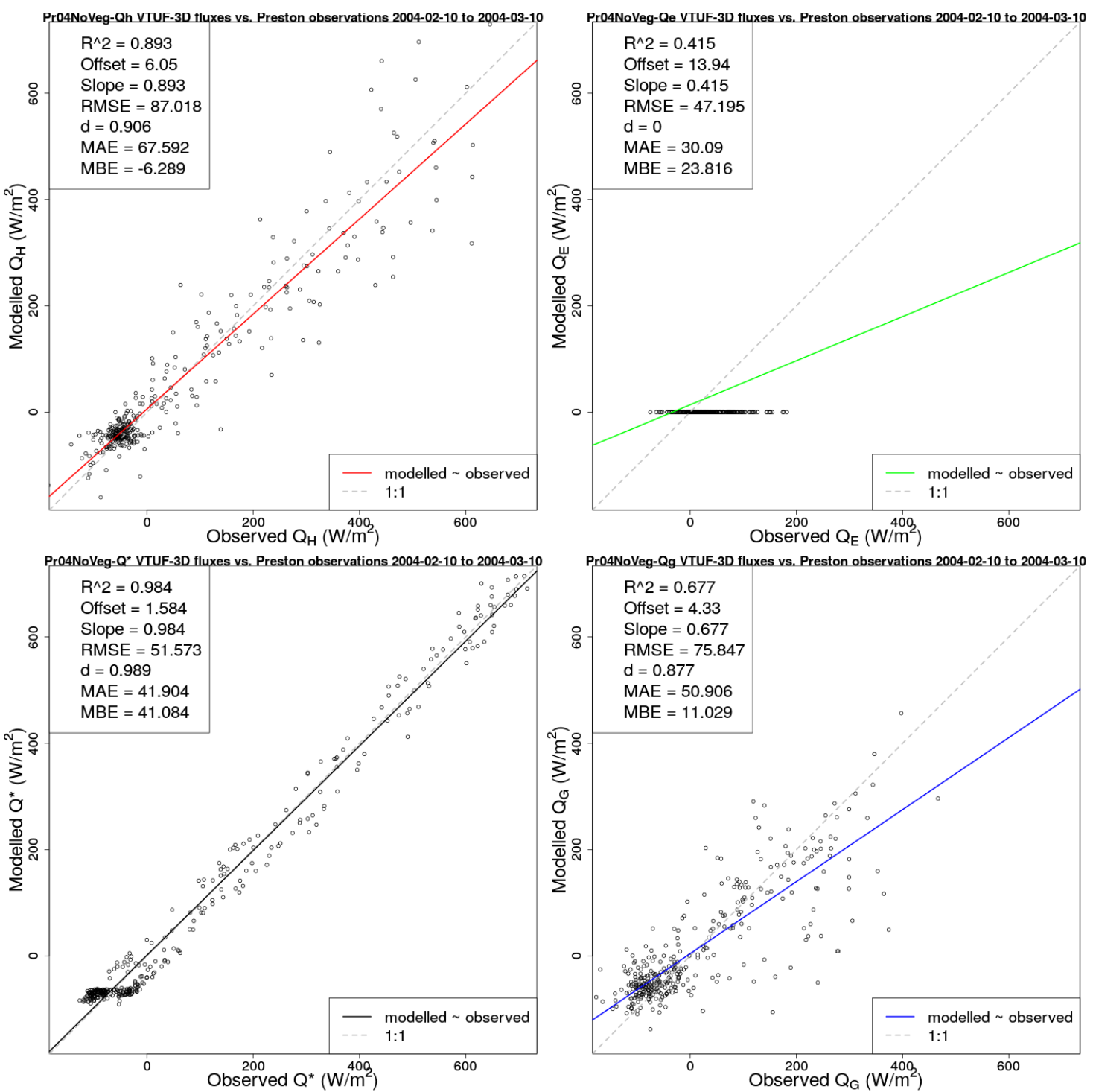

Figure 9: Pr04NoVeg scenario modelled vs. observations for $Q_{H}, Q_{E}, Q^{*}$, and $Q_{G}$ fluxes for the period 10 February-10 March 2004. 
Our approach uses an innovative method, the first time vegetation has been tiled and incorporated into a microscaled surface energy balance model in this manner. This method was anticipated to bring performance improvements over the previous version of the model that did not consider vegetation. The results suggest that this is the case, shown in the the results of the Pr04NoVeg no vegetation evaluation scenario. In comparison with other urban models, VTUF3D has shown comparable performance while delivering micro-scale results. In addition to the improved modelling performance, the addition of vegetation has dramatically improved the applicability of VTUF-3D to a wide range of modelling problems. Indeed, without this addition, the main aim of this model, to determine the thermal comfort improvements due to urban vegetation and water, would not be possible.

Despite these improvements to the modelling tool, the fluxes of $Q_{E}$ show some divergence from the observations. The divergence was anticipated as there are three current limitations of VTUF-3D that can account for low $Q_{E}$ levels that need addressing in future versions of the model. The first limitation is not accounting for precipitation on impervious surfaces. Many spikes of $Q_{E}$ fluxes are seen in the observations shortly after rainfall. Demuzere et al. (2014) found evaporation from impervious surfaces in urban areas after rainfall can contribute an approximately $10 \%$ increase of $Q_{E}$ over a two month period, while Wouters et al. (2013) found increases of $45 \mathrm{~W} \mathrm{~m}^{-2}$ in $Q_{E}$ for up to 12 hours of daylight following rainfall. In other parameters, there is evidence that wet impervious surfaces can have some other short term cooling impacts. Hendel et al. (2016) observed that hourly watering of urban pavement during heat wave conditions could deliver maximum air temperature reductions (at $1.5 \mathrm{~m}$ above ground level) of $0.79{ }^{\circ} \mathrm{C}$ as well as $T_{m r t}$ and UTCI reductions of $1.67^{\circ} \mathrm{C}$ and $1.03^{\circ} \mathrm{C}$ respectively. While this last study might indicate an upper bound to the impact of wet pavement, until this portion of precipitation received is accounted for in VTUF-3D, care should be taken when modelling periods that contain precipitation.

The second limitation is not accounting for irrigation. While Melbourne was under Stage 2 water restrictions during the observation/modelling period (Melbourne Water, 2016), there would have been some amount of irrigation occurring to contribute to greater observed $Q_{E}$ fluxes than modelled. Estimates of household irrigation during February 2004 are of frequencies of 2.8 times a week (3.1 for only the homes which irrigate) with average irrigation flows of $16.3 \mathrm{slm}$ (standard litre per minute) and average durations of 46 minutes per irrigation event (Roberts, 2005). Irrigation is an important limitation that needs addressing as quantifying the benefits of irrigation as part of WSUD is another intended use of this model.

The third limitation is that the full diversity of vegetation and trees of the modelled area is not represented in the modelled domain. In this study, parametrisations were included for grass and two evergreen tree species. However, the number of vegetation parametrisations is not a limitation in the model itself, as any type of vegetation can be plugged into the model. To overcome this deficit, more work needs to be done. Completion of each parametrisation is a time consuming process requiring numerous observations of tree physiology specifications, or specifying parameters from the literature. A standard limitation of many empirical models requiring a choice of either deciduous or evergreen vegetation does not exist in the model itself as these new vegetation types can include either, as long as the proper observations and parametrisations are completed on each type.

Another consideration is that the under-prediction of $Q_{E}$ is likely contributing to the over-estimating of $Q_{G}$ (calculated as a residual in MAESPA vegetation tiles). An improvement in modelling of the $Q_{E}$ fluxes will likely lead to an improvement in the modelled $Q_{G}$ fluxes. Finally, values of $Q_{F}$, anthropogenic heat $\left(\mathrm{W} \mathrm{m}^{-2}\right)$, are not accounted for in the VTUF-3D model, but contribute to the total $Q_{H}$ fluxes in the observations. Flux values for this modelling and observation period (summertime) are anticipated to contribute peaks of over $15 \mathrm{~W} \mathrm{~m}^{-2}$ for low density areas of cities and peaks of 30-60 $\mathrm{W} \mathrm{m}^{-2}$ for medium density areas (Sailor and $\mathrm{Lu}, 2004$ ). In both the observations and modelling results, these unaccounted fluxes will be present in the errors for the four observed and modelled fluxes.

\subsection{Spatial and temporal mean radiant temperature and human thermal comfort index evaluation}

While evaluation against the Preston flux observations indicates that VTUF-3D performed well in partitioning the basic energy fluxes, there are a number of other aspects that need to be evaluated. Given the intended application of the model to assess the impacts of urban greening on HTC at a micro-climate scale, a demonstration of accurate predictions of $T_{m r t}$ and HTC indices is an important step. Both parameters are highly influential for thermal comfort and capture the effects of varied shading across an urban canyon. Observational studies have shown that street orientation, tree placement on the street, and canopy cover amounts can cause large micro-climate variations in HTC and of $T_{m r t}$ (Sanusi et al., 2016; Oliveira et al., 2011; Ali-Toudert and Mayer, 2007). The evaluation will be performed by 
comparing predicted spatial values of $T_{m r t}$ and UTCI to observed values. Note, evaluations of spatial air temperature $\left(T_{a}\right)$ will not be possible as VTUF-3D only predicts air temperature as a single canyon-wide value and not spatially.

\subsubsection{George St. and Gipps St. dataset overview}

This set of evaluations was undertaken using observations from George St. and Gipps St. in the City of Melbourne (Coutts et al., 2015b). Observations were taken at a number of observation stations, recording air temperature, wind speed, humidity, and incoming short wave radiation, located along the two streets. The purpose of the study was to observe and quantify the effects of street trees on HTC and recorded observations in streets with varied canopy cover. Figure 10 shows the two streets used in this evaluation.

The two streets both have a shallow urban canyon, characterised as LCZ6B (open low-rise) (Stewart and Oke, 2012), and both are orientated E-W. Gipps St. contains a very limited canopy cover and is designated open (OPN) in the observation study. George St. contains a dense canopy cover and is designated as treed (TRD). Some of the sensors were located directly under tree canopies and others located in the open. A main purpose of the VTUF-3D model will be to evaluate the impacts of different arrangements urban vegetation on HTC in urban canyons. Differing amounts of canopy cover are a major factor of these different arrangements. Because of this, an evaluation using observations from two very similar streetscapes which mainly differ in the amount of canopy cover was an ideal evaluation of VTUF-3D's spatial accuracy (of $T_{m r t}$ and $T_{s f c}$ predictions) in resolving the impacts of different arrangements and quantities of urban greenery on HTC.

Tree cover of Gipps St consists of Ulmus parvifolia (Chinese Elm) with a median height of 9.5m and crown diameter of $9.6 \mathrm{~m}$. The limited tree cover of George St. also consists of $U$. parvifolia. The entire street canyon floor of both streets are impervious, consisting of concrete and asphalt, with the exception of a small pervious area of $1.2 \mathrm{~m}^{2}$ surrounding each tree in the road areas. General characteristics of the two sites are summarised in Table 6.

Table 6: Gipps/George St. evaluation site characteristics (Coutts et al., 2015b).

\begin{tabular}{|l|l|l|}
\hline Property & Gipps St. (OPN) & George St. (TRD) \\
\hline Observation stations & 5 & 7 \\
\hline Minimum building height $(\mathrm{m})$ & 4 & 4 \\
\hline Maximum building height $(\mathrm{m})$ & 14 & 11 \\
\hline Average building height $(\mathrm{m})$ & 7 & 8 \\
\hline Street width $(\mathrm{m})$ & 25 & 25 \\
\hline Mean H:W & 0.27 & 0.32 \\
\hline Plan area canopy cover $(\%)$ & 12 & 45 \\
\hline
\end{tabular}

Observations were taken at heights of 3.5 to $4.0 \mathrm{~m}$ on existing light poles at locations indicated in Figure 10. The observation period was for 21 months, from October 2011 to June 2013. Each observation station recorded air temperature, wind speed, humidity, incoming shortwave, and black globe temperature. For each station, mean radiant temperature was calculated using a formula of Kántor and Unger (2011), with a modified convective coefficient specific to the globes used in the observations (Coutts et al., 2015b, 2016b). UTCI was calculated using RayMan Pro 2.1 (Matzarakis et al., 2010) for a 35 year old male, clothing factor of 0.9 , and activity rate of $80 \mathrm{~W}$. This temperature was then compared to Bröde et al. (2012) assessment scale of thermal stress.

Station locations (noted with white labels on Figure 10) are shown in the modelled domains for both streets. Stations for George St. are referred to as TRD_2, TRD_3, TRD_4, and TRD_5. Stations for Gipps St. are referred to as OPN_3, OPN_4, OPN_5. These domains were configured accordingly using a 100x100m subset of the two streets (Figure 10) with a domain resolution of $5 \mathrm{~m}$ grids. Building heights and locations and vegetation location and heights for both streets are shown in Figure 11. Model parameters were set to the values given in Table 7. Most of these values are TUF-3D default values, from Krayenhoff and Voogt (2007). Vegetation settings for the mix of two tree types (olive and brushbox) as well as grass are set to the values given in the model design vegetation parametrisation section (Appendix A).

The two evaluation simulations (designated GeorgeValidation and GippsValidation) were run for 30 days between the dates 31 January 2012 and 1 March 2012, forced by the observations (of observation station OPN_1) from Coutts et al. (2015b) for those days. Values used from the observations include air temperature, wind speed, and wind 

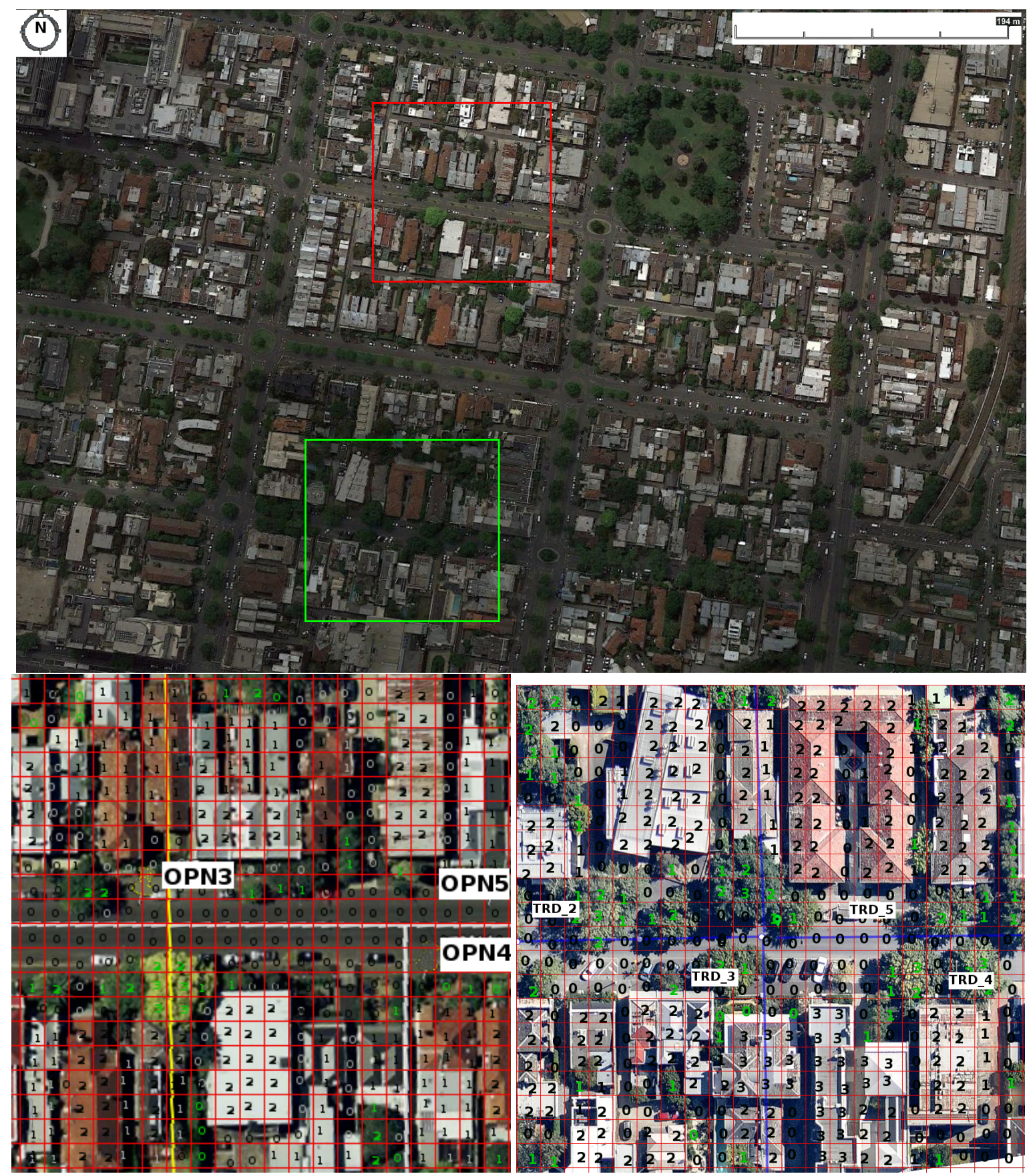

Figure 10: Overview of observed City of Melbourne locations: Gipps St. (OPN), outlined in red, and George St. (TRD), outlined in green. Gipps St./George St. - Modelled domains with 3 and 4 observation stations located on street, gridded at $5 \mathrm{~m}$ resolution (numbers showing building/vegetation heights in $5 \mathrm{~m}$ multiples). Adapted from Google Maps (2015). 

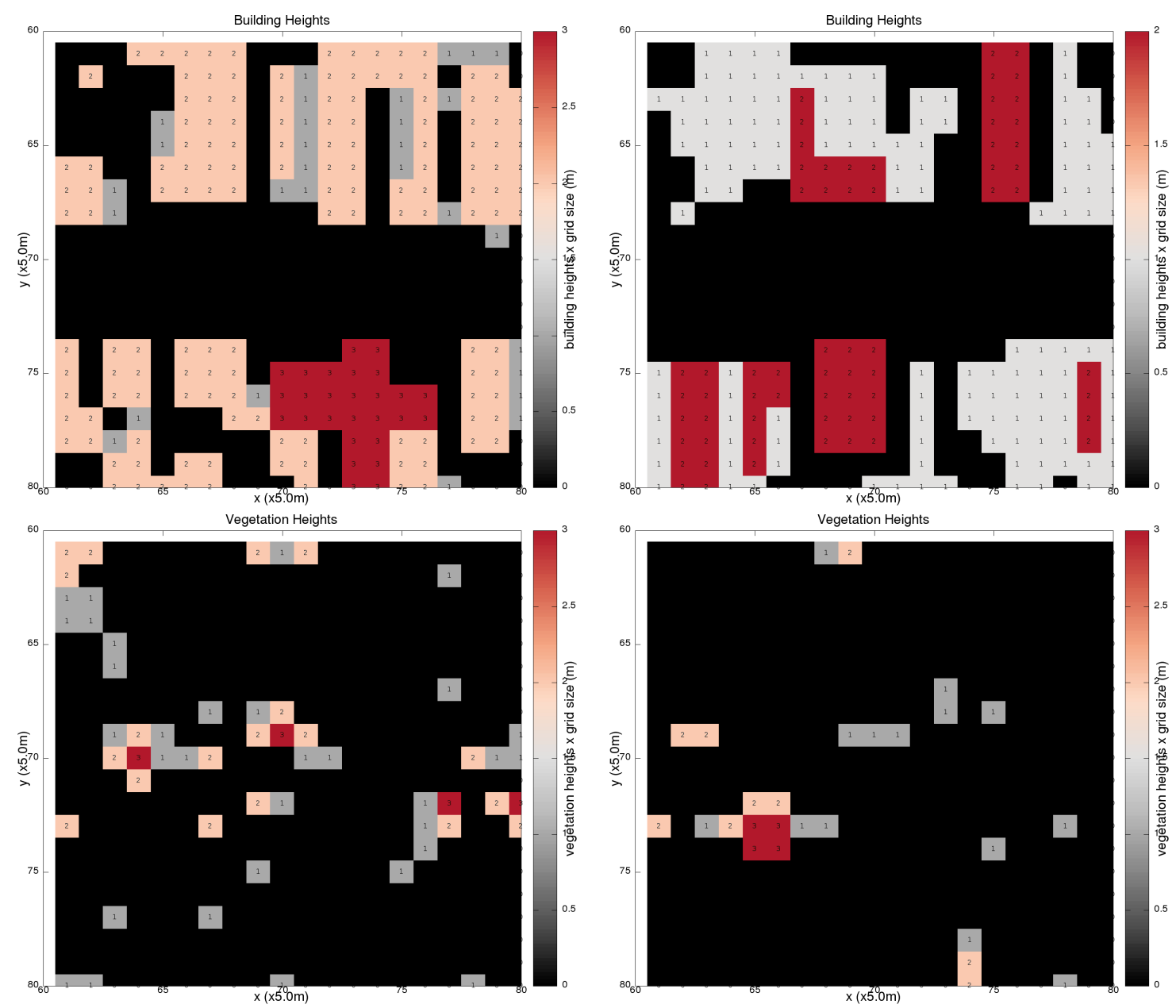

Figure 11: Building heights (top) / Vegetation cover (bottom) - George St (left), Gipps St. (right).

Table 7: George/Gipps St. evaluation scenario model parameters.

\begin{tabular}{|l|l|l|}
\hline Parameter & Value(s) & Source \\
\hline Albedo (roof, street, wall) & $0.15,0.10,0.30$ & Krayenhoff and Voogt (2007) \\
\hline Emissivity (roof, street, wall) & $0.92,0.92,0.88$ & Krayenhoff and Voogt (2007) \\
\hline Forcing data height (m) & 4.0 & Coutts et al. (2015b) \\
\hline Mean height of buildings, George St./Gipps St. (m) & $9.4,6.8$ & Calculated from domain \\
\hline Mean height of trees, George St./Gipps St. (m) & $7.45,8.14$ & Calculated from domain \\
\hline Initial $T_{s f c}$ (roof, street, wall) $\left({ }^{\circ}\right)$ & $18.0,23.0,22.0$ & Krayenhoff and Voogt $(2007)$ \\
\hline $\begin{array}{l}\text { Constant building internal air temperature (base of roofs } \\
\text { and walls) }\left({ }^{\circ} \mathrm{C}\right)\end{array}$ & $22.0,20.0$ & Krayenhoff and Voogt $(2007)$ \\
\hline Constant deep-ground temperature $\left({ }^{\circ} \mathrm{C}\right)$ & 19.0 & Krayenhoff and Voogt $(2007)$ \\
\hline Constant building internal floor temperature $\left({ }^{\circ} \mathrm{C}\right)$ & 15.0 & Krayenhoff and Voogt $(2007)$ \\
\hline
\end{tabular}


direction. Values for $L \downarrow$ and air pressure are taken from Melbourne Airport observations (station 086282, Melbourne Airport) (Bureau of Meteorology, 2016a). Values for $K \downarrow$ are taken from one minute solar observations (station 086282, Melbourne Airport) (Bureau of Meteorology, 2016b). For full radiation vegetation runs, the mean global irradiance was used while for diffuse runs, the mean diffuse irradiance was used. In addition, the MAESPA FBEAM variable (fraction of incident PAR which is direct-beam) is set to 0.0 in the forcing data for diffuse runs. Values of $\mathrm{CO}_{2}$ for vegetation forcing files were set to a constant of $450 \mathrm{ppm}$ throughout the modelling period.

The period covered contains a range of conditions, as shown in Figure 12. The period especially features a number of hot days (over $30^{\circ} \mathrm{C}$ ). As one of the major applications of VTUF-3D will be examining high temperature moderation, evaluation over a period containing these hot days is important. This observation period contains no days with precipitation.

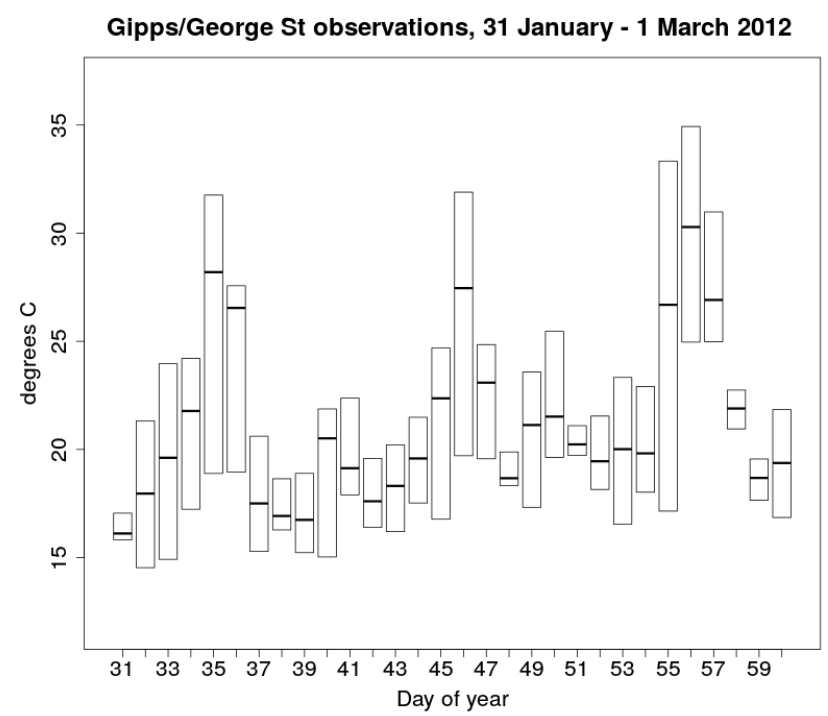

Figure 12: Daily maximum, minimum, and mean air temperature observations of Gipps/George St. during the evaluation period of 31 January - 1 March 2012.

In the Coutts et al. (2015b) observations for this modelled period, the open canyon of Gipps St. shows very little variation in $T_{m r t}$ across the locations while the treed canyon of George St. shows wide variations, especially between stations TRD_2 and TRD_3. TRD_4, a highly exposed location, shows the highest $T_{m r t}$ values in the late mornings, warming quicker than all the other locations, as well as reaching the highest afternoon peak. TRD_3 warms the slowest in the mornings, with early morning building shade with continued early afternoon canopy shading. TRD_2 and TRD_5 also warm slowly in the mornings due to building shading and vegetation shading respectively and both reach a reduced afternoon peak (compared to TRD_4). All observation stations come back into closer agreement in the late afternoons.

\subsubsection{George/Gipps St. evaluation results}

Modelled predictions for the George St. observation locations (TRD_2, TRD_3, TRD_4, and TRD_5) and Gipps St. observation locations (OPN_3, OPN_4, and OPN_5) were extracted from the results of the GeorgeValidation and Gipps Validation scenarios and compared to the observations for those locations. Statistical analysis (RMSE, MBE, MAE, and d index of agreement) for these four and three locations for $T_{m r t}$ and UTCI are summarised in Table 8.

To examine the variations between the different observation points, the three locations for Gipps St. (OPN_3, OPN_4, and OPN_5) were aggregated into hourly averages over 30 days and compared to the same aggregation of the modelled results. A similar analysis was performed for modelled and observed UTCI for Gipps St. Finally, both 
Table 8: George St. GeorgeValidation and Gipps St. GippsValidation scenarios $T_{m r t}$ and UTCI predicted vs. observations statistical performance of $\operatorname{RMSE}\left({ }^{\circ} \mathrm{C}\right), \operatorname{MBE}\left({ }^{\circ} \mathrm{C}\right), \operatorname{MAE}\left({ }^{\circ} \mathrm{C}\right)$, and d index of agreement.

\begin{tabular}{|c|c|c|c|c|c|c|c|c|}
\hline & \multicolumn{4}{|c|}{$T_{m r t}$} & \multicolumn{4}{c|}{ UTCI } \\
Observation point & RMSE & MBE & MAE & d & RMSE & MBE & MAE & d \\
\hline TRD_2 & 5.48 & -2.59 & 3.88 & 0.938 & 3.02 & -2.58 & 2.72 & 0.931 \\
\hline TRD_3 & 6.46 & 0.24 & 3.58 & 0.925 & 2.74 & -1.65 & 2.38 & 0.947 \\
\hline TRD_4 & 7.94 & -4.29 & 5.05 & 0.913 & 3.64 & -2.93 & 3.03 & 0.914 \\
\hline TRD_5 & 6.74 & 1.30 & 4.28 & 0.939 & 2.75 & -1.58 & 2.41 & 0.953 \\
\hline OPN_3 & 6.01 & -0.28 & 3.90 & 0.959 & 2.33 & -0.98 & 1.80 & 0.971 \\
\hline OPN_4 & 6.11 & -0.99 & 3.84 & 0.959 & 2.44 & -1.09 & 1.98 & 0.967 \\
\hline OPN_5 & 5.82 & -1.12 & 3.52 & 0.961 & 2.45 & -1.15 & 2.01 & 0.965 \\
\hline
\end{tabular}

analyses were repeated for the four locations of George St. (TRD_2, TRD_3, TRD_4, and TRD_5). The results for all of these are presented in Figure 13
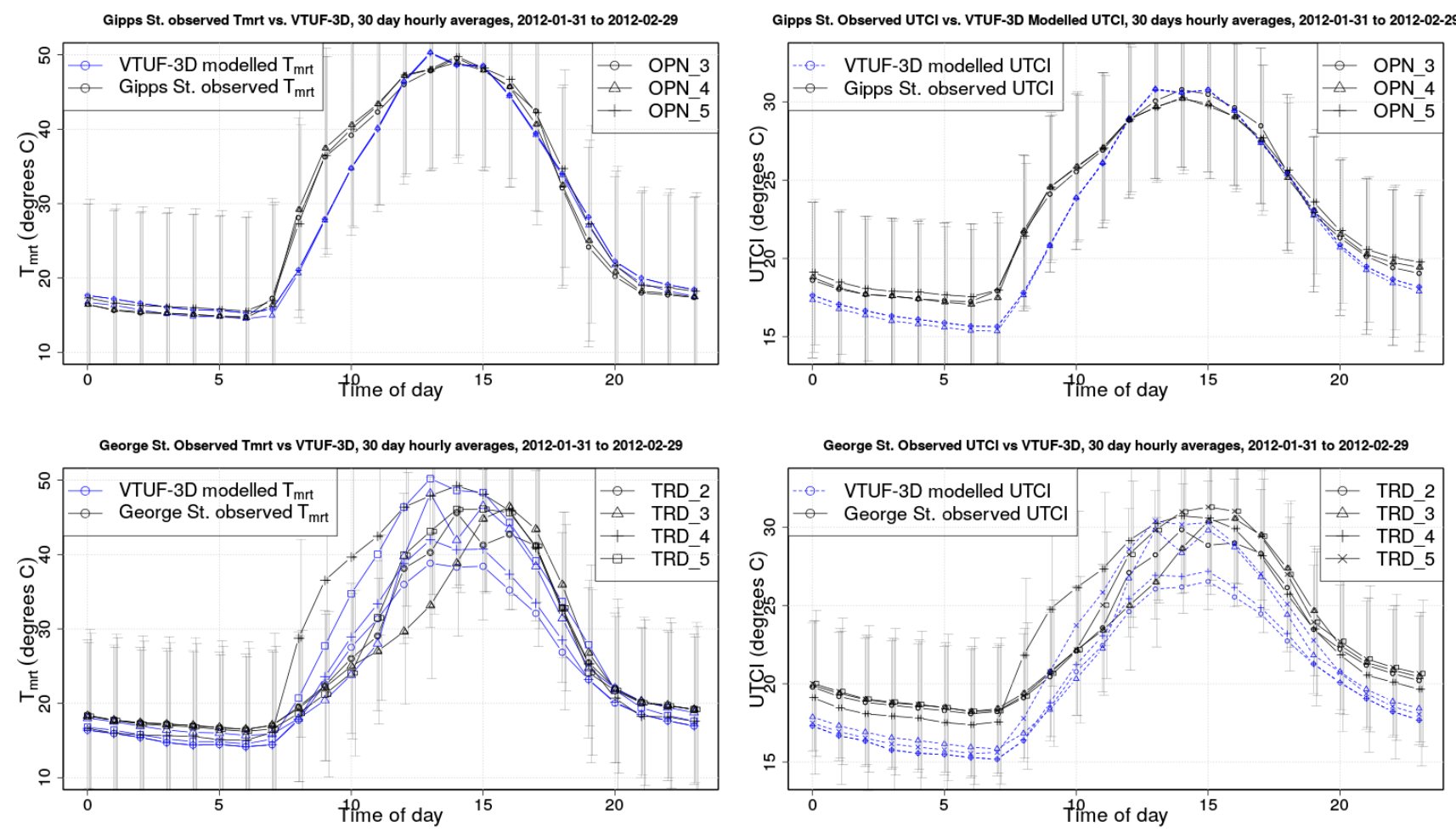

Figure 13: Gipps St. GippValidation scenario three observation stations (OPN_3, OPN_4, and OPN_5) values of $T_{m r t}$ and UTCI aggregated into hourly averages over 30 days compared to modelled points, with error bars at observation standard deviations. George St. GeorgeValidation scenario four observation stations (TRD_2, TRD_3, TRD_4, and TRD_5) values of $T_{m r t}$ and UTCI aggregated into hourly averages over 30 days compared to modelled points, with error bars at observation standard deviations

The modelled results of $T_{m r t}$ for Gipps St., a clear open street with few obstructions, follow closely to the observed values for the three point locations. Variations from the diurnal trends in the observations are seen in a slower warming of the model during the mornings. Very similar patterns are seen in the Gipps St. modelled diurnal trends of UTCI, of which $T_{m r t}$ is a main driver.

There are a number of differences in the way $T_{g}$ (and its use in calculating $T_{m r t}$ ) (see Section 2.4 and Eq. 6) is calculated compared to the observed values that could explain some of the differences. The modelled results are 
calculated for each surface in the domain (and only for surfaces in the domain). As there are no surfaces at the locations at which the observations were taken ( 3.5 to $4 \mathrm{~m}$ above the ground), the comparisons of $T_{m r t}$ needed to be performed on the modelled results at a $0 \mathrm{~m}$ height underneath the observation locations. These modelled ground surfaces will have received reduced amounts of $K \downarrow$ due to a reduced sky view factor and shading effects, especially in the mornings when much of the canyon floor will be in shadow due to lower sun angles.

Modelled results of $T_{m r t}$ and UTCI in George St. the treed canyon, follow similar patterns to Gipps St. The observations show wide variations between the observation locations due to the intermittent shading effect through a denser canopy as the sun moves across the sky. The modelled results also show wide variations between the locations but do not reproduce as wide a range as the observations. Additionally, differences can be seen in timing of periods of shading and illumination compared to the observations.

A statistical analysis of predicted vs. observed results is presented in Table 8. Results of d index of agreement for $T_{m r t}$ and UTCI for the more complex treed canyon (George St.) show values of 0.91 to 0.93 while the open Gipps St. canyon shows superior performance in the range of 0.95 to 0.96 for $T_{m r t}$ and 0.95 to 0.97 for UTCI. Other statistics (RMSE, MBE, and MAE) also show this pattern of good performance within the open canyon compared to reduced performance in the treed canyon.

These wider divergences of modelled results from observed values within the treed canyon suggests a number of possible limitations of this study and of the VTUF-3D model. The first is of the evaluation process. High quality, high resolution observations of $T_{m r t}$ and UTCI in urban areas, particularly underneath a dense canopy, are difficult to make, and very few datasets are widely available for model evaluations. The small number of observed locations available within this evaluation led to difficulty in matching the precise position of the observation sensors (and the precise amounts of rapidly fluctuating illumination on the black globe sensors) to the more detailed resolution of the modelled results. The divergences also suggest some limitations of VTUF-3D when modelling dense vegetation. This can result from the challenges of designing an exact detailed representation of the observed area within the modelled domain using a 5m resolution, as small differences in timing can lead to large differences in the comparisons. It also suggests further work is needed to improve the detail of the physical representation of the vegetated canopy in the next version of VTUF-3D.

A comparison of modelled $T_{c a n}$ from scenarios GeorgeValidation and GippValidation to the observed $T_{a}$ of George St. four treed canopy stations and Gipps St. three open canopy stations is shown in Figure 14. These air temperature values were aggregated into hourly averages over the evaluation period. A direct comparison of these two data sets is difficult as the modelled $T_{c a n}$ values are averages of the entire urban canopy air space while the seven observation stations record the air temperatures at 3.5 to $4 \mathrm{~m}$ height for each specific location. The modelled $T_{\text {can }}$ of the open canopy street (Gipps St.) shows peak values approximately $1{ }^{\circ} \mathrm{C}$ warmer (as well as being overall warmer throughout daylight hours) than the treed street (George St.). Due to the difficulty in exact comparisons between averaged modelled street canyon air temperature and the point locations of the observations within the street canyon, the model over-estimates the air temperatures of each canyon as well as the relative difference between the two $\left(2^{\circ} \mathrm{C}\right.$ modelled vs. $1^{\circ} \mathrm{C}$ in the observations). However, the result does show that VTUF-3D can capture some of the relative cooling effects of increased canopy cover in air temperature predictions as seen in the Coutts et al. (2015b) observations.

\section{Summary and Conclusions}

This study presents the development of a new model, VTUF-3D, that is able to model vegetation and WSUD features, accounting for latent energy fluxes and their impacts on HTC. Two major modifications were made to the original TUF-3D model during the development of VTUF-3D. The first major modification added physical representations of vegetation and allow the shading effects of those features to be modelled. The second major modification added the ability to model vegetation physiological processes (and associated water cycles) and account for latent energy fluxes in surface energy balances.

VTUF-3D is a unique model involving an innovative tiling approach that accounts for the detailed physiological processes of vegetation. The model incorporates a templated scalable configuration system, used to represent specific types of vegetation, allowing any variety and mix of vegetation to be added to a modelled domain. Also, differential shading functionality allows impacts of urban geometry and inter-tree shading on vegetation anywhere in an urban canyon to be properly modelled. Finally, the addition of mean radiant temperature and UTCI output for all surfaces allows detailed analysis of the impact of vegetation on these important parameters influencing HTC in these areas. 


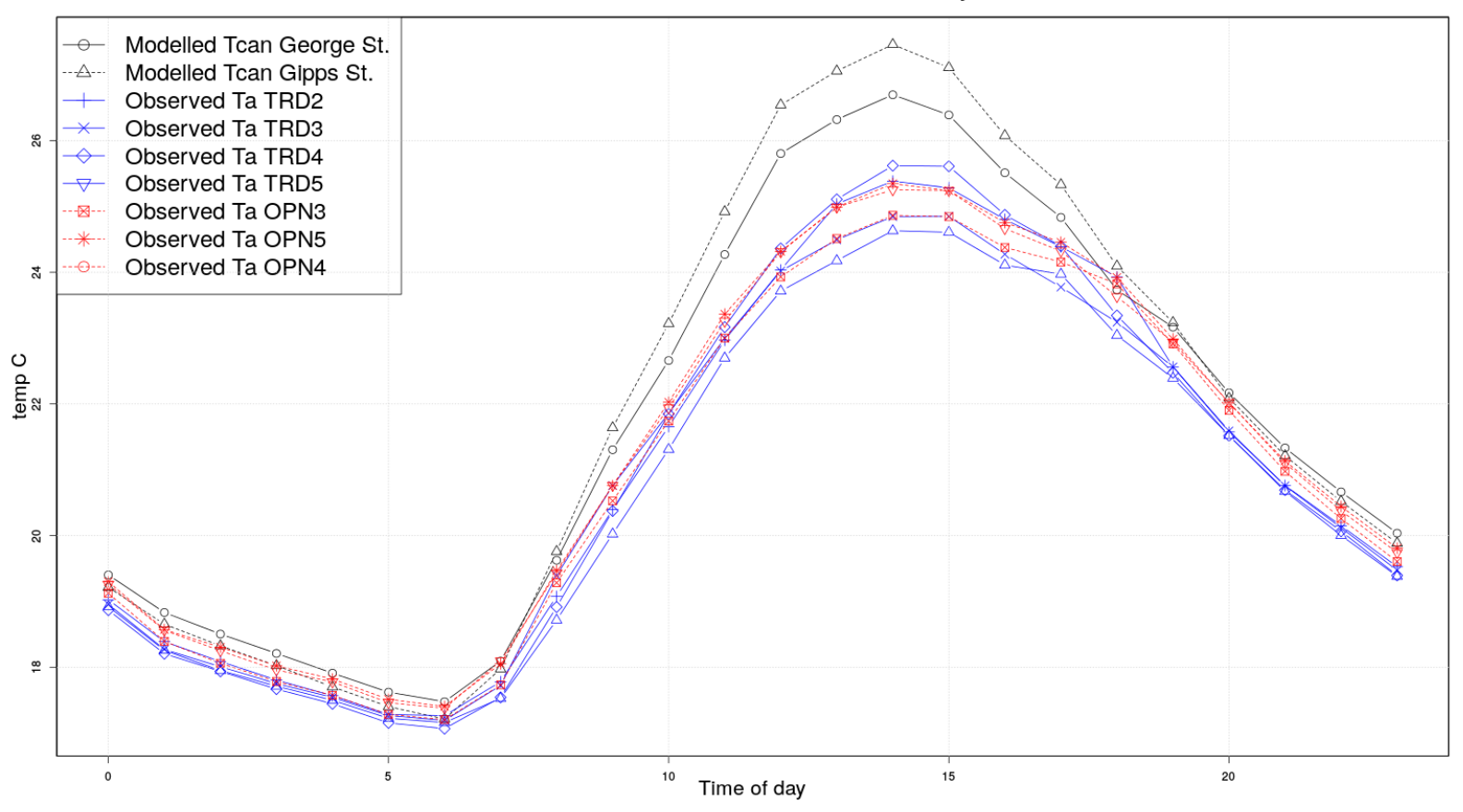

Figure 14: George/Gipps St. modelled $T_{\text {can }}$ from scenarios GeorgeValidation and GippValidation compared to observed $T_{a}$ of George St. 4 treed canopy stations and Gipps St. 3 open canopy stations, aggregated into hourly averages over February 2012 modelled period.

An extensive evaluation process has shown that VTUF-3D is able to accurately model urban areas (including urban vegetation). VTUF-3D has shown significant improvement over the unimproved (non-vegetated) TUF-3D model. VTUF-3D performs well within the range of other types of land surface schemes. The strong advantage of VTUF-3D is that it is able to perform with this level of accuracy at a micro-scale. In reproducing diurnal trends of $T_{m r t}$, VTUF-3D is able to reproduce the overall trends well, except is slightly slow to warm during the mornings. In the treed canyon of George St., where wide variations between the observation stations are seen in the observations, VTUF-3D is able to reproduce much of those variations, though not the entire range.

A key design goal of VTUF-3D was to simplify the approach, maximising the efficiency and accessibility of the model for a wide audience, yet be accurate enough for these users to start investigating the impacts of urban greening. This trade-off leads to some potential limitations. The offline aspects of the model means that some interactions and exchanges are not accounted for in the model. Future development plans include an option to couple VTUF-3D with a mesoscale atmospheric model (an online approach), but until then, evolving interactions and feedback between the boundary layer and the urban canyon are not captured. In the George St. evaluation, the forcing data used, observations from within the canyon, can lead to reduced accuracy. However, this highlights the relative levels of accuracy that can still be obtained using this source of easily obtained forcing data. Finally, not accounting for longwave exchanges between urban vegetation and the urban canyon due to the offline vegetation modelling is a further limitations of the current model. Future model development to bring the vegetation online into the model will eliminate this problem.

Now, with the completion and evaluation of the VTUF-3D v1.0 model, there is a suitable tool to model and study in detail the impacts of urban greening on HTC and provide recommendations and guidelines on how to best use urban greenery to reduce urban temperatures. Questions can be answered as to the optimal arrangement of canopy cover to provide maximum benefits. Performance of future scenarios can also help inform responses to future challenges, both in terms of urban redesign and understanding how current urban design will respond to changing urban climate conditions.

With VTUF-3D's micro-climate resolution, urban areas can be studied in great detail and proper mitigation strategies designed for every section of the urban canyon, allowing effort to be focused on areas with the greatest need. 
VTUF-3D is sufficiently scaled to resolve human level interactions with their surroundings and provide variables to calculate HTC (such as $\mathrm{T}_{m r t}$ ). The built in output of $\mathrm{T}_{m r t}$ and UTCI allows examination of these values without requiring additional steps. Finally, with the ability to insert any type of vegetation using physiological and physical vegetation templates, VTUF-3D is applicable to an vast number of scenarios and modelling questions. This new model will allow research into a wide variety of urban morphologies, quantifying the benefits of a wide variety of urban arrangements and allow planning for future changes and challenges in climate and urban design.

However, the creation and evaluation of VTUF-3D is only a first step. As the intended end users of the knowledge gained through VTUF-3D, planners and policy makers often lack the time, expertise, and scientific rigour needed to generate and interpret climate model output (Elasson, 2000; Moser, 2014; Winkler et al., 2011), work will need to be done with VTUF-3D to systematically analyse a wide variety of scenarios seeking optimal uses of urban vegetation for HTC and to summarise these findings. A forthcoming paper will start this process with an examination of varying urban canopy cover on HTC in street canyons using VTUF-3D. VTUF-3D has also been adopted by the CRC for Water Sensitive Cities as their micro-climate tool to evaluate climatic impacts of WSUD, with those findings disseminated to industry partners and the public at large. Finally, work is under way to provide a simpler user interface to VTUF-3D, allowing a wider adoption beyond the current academic research user-base.

\section{Code availability}

Development of VTUF-3D was conducted in FORTRAN 2003 (GNU, 2016a) in Netbeans 8.0.2 (Netbeans, 2016) and compiled with gfortran 4.8.4 (GNU, 2016b) on Ubuntu 14.04, but the code should compile on any platform with FORTRAN 2003 support. The original source code for TUF-3D was obtained from the author (Krayenhoff and Voogt, 2007), while source code for MAESPA was obtained from the MAESPA repository (Duursma, 2016). The development process merged these code bases and added the additional functionality described in this paper. The VTUF-3D source code is available at Nice (2017).

Model configuration process was developed in Java using the JRE 1.7.0 (Oracle, 2016) in Eclipse 4.5.2 (Eclipse Foundation, 2016). Data analysis and graphing scripts were generated in R (R Core Team, 2013) and Python (Python Software Foundation, 2016) using the Matplotlib library (Hunter, 2007).

\section{Acknowledgements}

The support of the Commonwealth of Australia through the Cooperative Research Centre program is acknowledged.

\section{References}

Alexander, L. V., Arblaster, J, M., 2009. Assessing trends in observed and modelled climate extremes over Australia in relation to future projections. International Journal of Climatology 435 (July 2008), 417-435.

Ali-Toudert, F., Mayer, H., 2006. Numerical study on the effects of aspect ratio and orientation of an urban street canyon on outdoor thermal comfort in hot and dry climate. Building and Environment 41 (2), 94-108.

URL http: //linkinghub.elsevier.com/retrieve/pii/S0360132305000120

Ali-Toudert, F., Mayer, H., 2007. Effects of asymmetry, galleries, overhanging façades and vegetation on thermal comfort in urban street canyons. Solar Energy 81 (6), 742-754.

URL http://linkinghub.elsevier.com/retrieve/pii/S0038092X06002623

Bailey, B. N., Overby, M., Willemsen, P., Pardyjak, E. R., Mahaffee, W. F., Stoll, R., 2014. A scalable plant-resolving radiative transfer model based on optimized GPU ray tracing. Agricultural and Forest Meteorology 198-199, 192-208.

Bailey, B. N., Stoll, R., Pardyjak, E. R., Miller, N. E., 2016. A new three-dimensional energy balance model for complex plant canopy geometries: Model development and improved validation strategies. Agricultural and Forest Meteorology 218-219 (February), $146-160$.

Baldini, E., Facini, O., Nerozzi, F., Arboree, C., 1997. Leaf characteristics and optical properties of different woody species. Trees $12,73-81$.

Ball, J. T., Woodrow, I. E., Berry, J. A., 1987. A model predicting stomatal conductance and its contribution to the control of photosynthesis under different environmental conditions. In: Biggins, J. (Ed.), Progress in Photosynthesis Research. No. 953. Martinus-Nijhoff Publishers, Dordrecht, the Netherlands, pp. 221-224.

Beardsell, D. V., Considine, J. A., 1987. Lineages, Lineage Stability and Pattern Formation in Leaves of Variegated Chimeras of Lophostemon confertus (R. Br.) Wilson \& Waterhouse and Tristaniopis laurina (Smith) Wilson \& Waterhouse (Myrtaceae). Aust. J. Bot. 35 (6), $701-714$. URL http://www.publish.csiro.au/paper/BT9870701

Bernacchi, C. J., Singsaas, E. L., Pimentel, C., Portis, A. R., Long, S. P., 2001. Improved temperature response functions for models of Rubiscolimited photosynthesis. Plant, Cell and Environment 24 (2), 253-259. 
Best, M. J., Grimmond, C. S. B., 2012. Analysis of the Seasonal Cycle Within the First International Urban Land-Surface Model Comparison. Boundary-Layer Meteorology 146 (3), 421-446.

Bijoor, N. S., Pataki, D. E., Haver, D., Famiglietti, J. S., 2014. A comparative study of the water budgets of lawns under three management scenarios. Urban Ecosystems 17 (4), 1095-1117.

Bodnaruk, E., Kroll, C., Yang, Y., Hirabayashi, S., Nowak, D., Endreny, T., 2017. Where to plant urban trees? A spatially explicit methodology to explore ecosystem service tradeoffs. Landscape and Urban Planning 157, 457-467.

URL http://linkinghub.elsevier.com/retrieve/pii/S016920461630175X

Bowler, D. E., Buyung-Ali, L., Knight, T. M., Pullin, A. S., 2010. Urban greening to cool towns and cities: A systematic review of the empirical evidence. Landscape and Urban Planning 97 (3), 147-155.

Bröde, P., 2009. Program for calculating UTCI Temperature (UTCI) released for public use after termination of COST Action 730, UTCI, Version a 0.002 , October 2009.

Bröde, P., Fiala, D., Blazejczyk, K., Holmér, I., Jendritzky, G., Kampmann, B., Tinz, B., Havenith, G., 2012. Deriving the operational procedure for the Universal Thermal Climate Index (UTCI). International Journal of Biometeorology 56 (3), $481-494$.

Brown, R. H., Morgan, J. A., 1980. Photosynthesis of Grass Species Differing in Carbon Dioxide Fixation Pathways 1. Plant Physiology 66 (4), 541-544.

Bruse, M., 1999. The influences of local environmental design on microclimate- development of a prognostic numerical Model ENVI-met for the simulation of Wind, temperature and humidity distribution in urban structures. Ph.D. thesis, University of Bochum, Germany (in German).

Bureau of Meteorology, 2016a. Latest Weather Observations for Melbourne Airport. http://www.bom.gov.au/products/IDV60901/IDV60901.94866.shtml.

Bureau of Meteorology, 2016b. One Minute Solar Data. http:/www.bom.gov.au/climate/data/oneminsolar/about-IDCJAC0022.shtml.

Byrne, J., Sipe, N., Searle, G., 2016. Green around the gills? The challenge of density for urban greenspace planning in SEQ. Australian Planner 47 (3), 162-177.

Chen, Y. C., Lin, T. P., Matzarakis, A., 2014. Comparison of mean radiant temperature from field experiment and modelling: a case study in Freiburg, Germany. Theoretical and Applied Climatology 118 (3), 535-551.

Choudhury, B. J., Monteith, J. L., 1988. A four-layer model for the heat budget of homogeneous land surfaces. Q. J. Roy. Meteorol. Soc 114, 373-398.

City of Port Phillip, 2010. Greening Port Phillip: Street Tree Planting Guide 2010-2015. http://www.portphillip.vic.gov.au/street-tree-plantingguide-2010-2015.pdf.

Cohen, J. E., 2003. Human Population : The Next Half Century. Science 302 (5648), 1172-1175.

Coutts, A., Moore, C., Tapper, N. J., White, E. C., 2016a. Microclimate of isolated trees in the urban environment. In: 2nd Urban Tree Diversity Conference, Melbourne, Australia, 22-24 February 2016.

Coutts, A., Szota, C., Thom, J., 2015a. Passive irrigation of street trees to improve tree health and support urban cooling. In: 9 th International Conference on Urban Climate, 20-24 July 2015, Toulouse, France.

Coutts, A. M., 2014. Trees in the street canyon environment: Exposure and response under changing micro-climates and water availability. In: 11th Symposium on the Urban Environment, 94th AMS Annual Meeting, 2-6 February 2014, Atlanta, GA. pp. 1-20.

Coutts, A. M., Beringer, J., Tapper, N. J., 2007. Impact of Increasing Urban Density on Local Climate: Spatial and Temporal Variations in the Surface Energy Balance in Melbourne, Australia. Journal of Applied Meteorology and Climatology 46 (4), $477-493$.

URL http://journals .ametsoc.org/doi/abs/10.1175/JAM2462.1

Coutts, A. M., Tapper, N. J., Beringer, J., Loughnan, M., Demuzere, M., 2012. Watering our Cities: The capacity for Water Sensitive Urban Design to support urban cooling and improve human thermal comfort in the Australian context. Progress in Physical Geography 37 (1), $2-28$. URL http: //ppg.sagepub.com/cgi/doi/10.1177/0309133312461032

Coutts, A. M., White, E. C., Tapper, N. J., Beringer, J., Livesley, S. J., 2015b. Temperature and human thermal comfort effects of street trees across three contrasting street canyon environments. Theoretical and Applied Climatology 124 (1), 55-68.

URL http: //link.springer.com/10.1007/s00704-015-1409-y

Coutts, A. M., White, E. C., Tapper, N. J., Beringer, J., Livesley, S. J., 2016b. Erratum to: Temperature and human thermal comfort effects of street trees across three contrasting street canyon environments (Theor Appl Climatol, 10.1007/s00704-015-1409-y). Theoretical and Applied Climatology $126(3-4), 815$.

URL http://dx.doi.org/10.1007/s00704-016-1832-8

De Kauwe, M. G., Kala, J., Lin, Y.-S., Pitman, A. J., Medlyn, B. E., Duursma, R. A., Abramowitz, G., Wang, Y.-P., Miralles, D. G., 2015. A test of an optimal stomatal conductance scheme within the CABLE land surface model. Geoscientific Model Development 8 (2), $431-452$.

URL http://www.geosci-model-dev.net/8/431/2015/

Demuzere, M., Coutts, A., Göhler, M., Broadbent, A., Wouters, H., van Lipzig, N., Gebert, L., 2014. The implementation of biofiltration systems, rainwater tanks and urban irrigation in a single-layer urban canopy model. Urban Climate 10, 148-170.

URL http://dx.doi.org/10.1016/j.uclim.2014.10.012

Díaz-Espejo, A., Walcroft, A. S., Fernández, J. E., Hafridi, B., Palomo, M. J., Girón, I. F., 2006. Modeling photosynthesis in olive leaves under drought conditions. Tree Physiology 26 (11), 1445-1456.

Donovan, G. H., Butry, D. T., 2009. The value of shade: Estimating the effect of urban trees on summertime electricity use. Energy and Buildings $41(6), 662-668$.

DSE, 2002. Melbourne 2030, Planning for sustainable growth. http://www.nre.vic.gov.au/melbourne2030online/.

URL http://www.nre.vic.gov.au/melbourne2030online/

Duursma, R., 2016. A soil-plant-atmosphere model based on MAESTRA and SPA. https://bitbucket.org/remkoduursma/maespa.

Duursma, R. A., Medlyn, B. E., 2012. MAESPA: a model to study interactions between water limitation, environmental drivers and vegetation function at tree and stand levels, with an example application to [CO2] x drought interactions. Geoscientific Model Development 5 (4), 919-940. URL http://www.geosci-model-dev.net/5/919/2012/

Eclipse Foundation, 2016. Eclipse IDE for Java Developers, Version: Mars.2 Release (4.5.2).

Elasson, I., 2000. The use of climate knowledge in urban planning. Landscape and Urban Planning 48, 31-44. 
Federal Interagency Forum on Aging-Related Statistics, 2016. Federal Interagency Forum on Aging-Related Statistics. Older Americans 2016: Key Indicators of Well-Being. Washington, DC: U.S. Government Printing Office.

Federer, C., Vorosmarty, C., Fekete, B., 2003. Sensitivity of annual evaporation to soil and root properties in two models of contrasting complexity. Journal of Hydrometeorology 4, 1276-1290.

URL http://journals .ametsoc.org/doi/abs/10.1175/1525-7541(2003)004\%3C1276:SOAETS\%3E2.0.C0;2

Fernández, J. E., Moreno, F., Girón, I. F., Blázquez, O. M., 1997. Stomatal control of water use in olive tree leaves. Plant and Soil 190 (2), 179-192. Frank, S., Waters, G., Beer, R., May, P., 2006. An Analysis of the Street Tree Population of Greater Melbourne at the Beginning of the 21st Century. Arboriculture \& Urban Forestry 32 (July), 155-163.

Fung-yan, M., 1999. Hyperspectral Data Analysis of Typical Surface Covers in Hong Kong. Masters thesis, The Chinese University of Hong Kong. Gardner, W. R., 1960. Dynamic aspects of water availability to plants. Soil Sci. 89, 63-73.

Gilmanov, T. G., Soussana, J. F., Aires, L., Allard, V., Ammann, C., Balzarolo, M., Barcza, Z., Bernhofer, C., Campbell, C. L., Cernusca, A., Cescatti, A., Clifton-Brown, J., Dirks, B. O. M., Dore, S., Eugster, W., Fuhrer, J., Gimeno, C., Gruenwald, T., Haszpra, L., Hensen, A., Ibrom, A., Jacobs, A. F. G., Jones, M. B., Lanigan, G., Laurila, T., Lohila, A., G.Manca, Marcolla, B., Nagy, Z., Pilegaard, K., Pinter, K., Pio, C., Raschi, A., Rogiers, N., Sanz, M. J., Stefani, P., Sutton, M., Tuba, Z., Valentini, R., Williams, M. L., Wohlfahrt, G., 2007. Partitioning European grassland net ecosystem $\mathrm{CO} 2$ exchange into gross primary productivity and ecosystem respiration using light response function analysis. Agriculture, Ecosystems and Environment 121 (1-2), 93-120.

GNU, 2016a. FORTRAN 2002 - GCC Wiki. https://gcc.gnu.org/wiki/Fortran2003.

GNU, 2016b. gfortran - the GNU Fortran compiler, part of GCC. https://gcc.gnu.org/wiki/GFortran.

Google Maps, 2015. Preston, Victoria 3072.

Green, R., Beard, J., Casnoff, D., 1990. Leaf blade stomatal characterizations and evapotranspiration rates of 12 cool-season perennial grasses. HortScience 25 (7), 760-761.

URL http: //hortsci.ashspublications.org/content/25/7/760. short

Grimmond, C., Oke, T., 1999. Aerodynamic properties of urban areas derived from analysis of surface form. Journal of Applied Meteorology 38, 1262-1292.

URL http: //journals.ametsoc.org/doi/abs/10.1175/1520-0450(1999) 038\%3C1262\%3AAPOUAD\%3E2.0.CO\%3B2

Grimmond, C. S. B., Blackett, M., Best, M. J., Baik, J.-J., Belcher, S. E., Beringer, J., Bohnenstengel, S. I., Calmet, I., Chen, F., Coutts, A., Dandou, A., Fortuniak, K., Gouvea, M. L., Hamdi, R., Hendry, M., Kanda, M., Kawai, T., Kawamoto, Y., Kondo, H., Krayenhoff, E. S., Lee, S.-H., Loridan, T., Martilli, A., Masson, V., Miao, S., Oleson, K., Ooka, R., Pigeon, G., Porson, A., Ryu, Y.-H., Salamanca, F., Steeneveld, G., Tombrou, M., Voogt, J. A., Young, D. T., Zhang, N., 2011. Initial results from Phase 2 of the international urban energy balance model comparison. International Journal of Climatology 31 (2), 244-272. URL http://doi.wiley.com/10.1002/joc. 2227

Grimmond, C. S. B., Blackett, M., Best, M. J., Barlow, J., Baik, J.-J., Belcher, S. E., Bohnenstengel, S. I., Calmet, I., Chen, F., Dandou, A., Fortuniak, K., Gouvea, M. L., Hamdi, R., Hendry, M., Kawai, T., Kawamoto, Y., Kondo, H., Krayenhoff, E. S., Lee, S.-H., Loridan, T., Martilli, A., Masson, V., Miao, S., Oleson, K., Pigeon, G., Porson, A., Ryu, Y.-H., Salamanca, F., Shashua-Bar, L., Steeneveld, G.-J., Tombrou, M., Voogt, J., Young, D., Zhang, N., 2010. The International Urban Energy Balance Models Comparison Project: First Results from Phase 1. Journal of Applied Meteorology and Climatology 49 (6), 1268-1292.

URL http://journals .ametsoc .org/doi/abs/10.1175/2010JAMC2354.1

Hall, S. J., Learned, J., Ruddell, B., Larson, K. L., Cavender-Bares, J., Bettez, N., Groffman, P. M., Grove, J. M., Heffernan, J. B., Hobbie, S. E., Morse, J. L., Neill, C., Nelson, K. C., O’Neil-Dunne, J. P. M., Ogden, L., Pataki, D. E., Pearse, W. D., Polsky, C., Chowdhury, R. R., Steele, M. K., Trammell, T. L. E., 2016. Convergence of microclimate in residential landscapes across diverse cities in the United States. Landscape Ecology 31 (1), 101-117.

Hamin, E. M., Gurran, N., 2009. Urban form and climate change: Balancing adaptation and mitigation in the U.S. and Australia. Habitat International 33 (3), 238-245.

URL http://dx.doi.org/10.1016/j.habitatint.2008.10.005

Hendel, M., Gutierrez, P., Colombert, M., Diab, Y., Royon, L., 2016. Measuring the effects of urban heat island mitigation techniques in the field: Application to the case of pavement-watering in Paris. Urban Climate 16, 43-58.

URL http://dx.doi.org/10.1016/j.uclim.2016.02.003

Huang, L., Li, J., Zhao, D., Zhu, J., 2008. A fieldwork study on the diurnal changes of urban microclimate in four types of ground cover and urban heat island of Nanjing, China. Building and Environment 43, 7-17.

Hunter, J. D., 2007. Matplotlib: A 2D graphics environment. Computing In Science \& Engineering 9 (3), 90-95.

IPCC, 2013. Climate Change 2013: The Physical Science Basis. Contribution of Working Group I to the Fifth Assessment Report of the Intergovernmental Panel on Climate Change. Tech. rep., Intergovernmental Panel on Climate Change, Cambridge, United Kingdom and New York, NY, USA.

Järvi, L., Grimmond, C., Christen, A., 2011. The Surface Urban Energy and Water Balance Scheme (SUEWS): Evaluation in Los Angeles and Vancouver. Journal of Hydrology 411 (3-4), 219-237.

URL http://linkinghub.elsevier.com/retrieve/pii/S0022169411006937

Jenerette, G. D., Harlan, S. L., Stefanov, W. L., Martin, C. A., 2011. Ecosystem services and urban heat riskscape moderation: Water, green spaces, and social inequality in Phoenix, USA. Ecological Applications 21 (7), 2637-2651.

Kántor, N., Unger, J., 2011. The most problematic variable in the course of human-biometeorological comfort assessment - the mean radiant temperature. Open Geosciences 3 (1), 90-100.

Katjacnik, K., Vogel-Mikus, K., Gaberscik, A., 2014. Silicified structures affect leaf optical properties in grasses and sedge. Journal of Photochemistry and Photobiology B: Biology 130, 1-10.

Katsouyanni, K., Pantazopoulou, A., Touloumi, G., Selepidaki, I., Moustris, K., Asimakopoulos, D., Poulopoulou, G., Trichopoulos, D., 1993. Evidence for interaction between air pollution and high temperature in the causation of excess mortality. Archives of Environmental Health $75(6), 235-242$. 
Krayenhoff, E. S., Voogt, J. A., 2007. A microscale three-dimensional urban energy balance model for studying surface temperatures. BoundaryLayer Meteorology 123 (3), 433-461.

URL http://www . springerlink. com/index/10.1007/s10546-006-9153-6

Kunz, R., Khatib, I., Moussiopoulos, N., 2000. Coupling of mesoscale and microscale models - an approach to simulate scale interaction. Environmental Modelling \& Software 15 (6-7), 597-602. URL http://www.sciencedirect.com/science/article/pii/S1364815200000554

Levinson, R., Berdahl, P., Akbari, H., Miller, W., Joedicke, I., Reilly, J., Suzuki, Y., Vondran, M., 2007. Methods of creating solar-reflective nonwhite surfaces and their application to residential roofing materials. Solar Energy Materials and Solar Cells 91 (4), 304-314.

Liljegren, J. C., Carhart, R. A., Lawday, P., Tschopp, S., Sharp, R., 2008. Modeling the wet bulb globe temperature using standard meteorological measurements. Journal of Occupational and Environmental Hygiene 5 (10), 645-655.

Lindberg, F., Holmer, B., Thorsson, S., 2008. SOLWEIG 1.0-modelling spatial variations of 3D radiant fluxes and mean radiant temperature in complex urban settings. International Journal of Biometeorology 52 (7), 697-713. URL http://www.ncbi.nlm.nih.gov/pubmed/18523814

Loughnan, M. E., Nicholls, N., Tapper, N. J., 2010. When the heat is on: Threshold temperatures for AMI admissions to hospital in Melbourne Australia. Applied Geography 30 (1), 63-69. URL http://linkinghub.elsevier.com/retrieve/pii/S0143622809000514

Mariscal, M. J., Orgaz, F., Villalobos, F. J., 2000. Modelling and measurement of radiation interception by olive canopies. Agricultural and Forest Meteorology 100 (2-3), 183-197.

Mascart, P., Noilhan, J., Giordani, H., 1995. A modified parameterization of flux-profile relationships in the surface layer using different roughness length values for heat and momentum. Boundary-Layer Meteorology 72, 331-344. URL http://link. springer. com/article/10.1007/BF00708998

Masson, V., 2000. A physically-based scheme for the urban energy budget in atmospheric models. Boundary-Layer Meteorology 94 (3), $357-397$. URL http: //www.springerlink.com/index/X11713072476W703.pdf

Masson, V., 2002. Evaluation of the Town Energy Balance (TEB) scheme with direct measurements from dry districts in two cities. Journal of Applied Meteorology 41 (2000), 1011-1026. URL http: //journals.ametsoc.org/doi/pdf/10.1175/1520-0450(2002)041\%3C1011\%3AEOTTEB\%3E2.0.CO\%3B2

Matzarakis, A., Rutz, F., Mayer, H., 2007. Modelling radiation fluxes in simple and complex environments-application of the RayMan model. International Journal of Biometeorology 51 (4), 323-34. URL http: //www.ncbi.nlm.nih.gov/pubmed/17093907

Matzarakis, A., Rutz, F., Mayer, H., 2010. Modelling radiation fluxes in simple and complex environments: basics of the RayMan model. International Journal of Biometeorology 54 (2), 131-9. URL http://www.ncbi.nlm.nih.gov/pubmed/19756771

Medlyn, B. E., Pepper, D. A., Grady, A. P. O., 2007. Linking leaf and tree water use with an individual-tree model. Tree Physiology $27,1687-1699$.

Medlyn, B. E., Robinson, A. P., Clement, R., McMurtrie, R. E., 2005. On the validation of models of forest CO2 exchange using eddy covariance data: some perils and pitfalls. Tree Physiology 25 (7), 839-857.

Melbourne Water, 2016. History of our water supply system. http://www.melbournewater.com.au/aboutus/historyandheritage/history-of-our-watersupply-system/pages/history-of-our-water-supply-system.aspx.

Monson, R. K., Littlejohn, Jr., R. O., Williams, III, G. J., 1982. The quantum yield for CO2 uptake in C3 and C4 grasses. Photosynthesis Research $3(2), 153-159$.

Monteith, J. L., 1965. Evaporation and environment. Symposia of the Society for Experimental Biology 19, $205-234$.

Moser, S. C., 2014. Communicating adaptation to climate change: the art and science of public engagement when climate change comes home. WIREs Clim Change 5 (3), 337-358.

URL http: //doi.wiley.com/10.1002/wcc. 276

Nearmap, 2015. Preston, Victoria 2072.

Netbeans, 2016. Netbeans Integrated Development Environment 8.0.2.

Nice, K. A., 2017. VTUF-3D code repository: VTUF-3D initial release [Data set]. Zenodo. http://doi.org/10.5281/zenodo.260064.

Nicholls, N., Skinner, C., Loughnan, M., Tapper, N., 2008. A simple heat alert system for Melbourne, Australia. International Journal of Biometeorology $52(5), 375-84$. URL http://www.ncbi.nlm.nih.gov/pubmed/18058138

Norman, J. M., 1979. Modelling the complete crop canopy. In: Barfield, B., Gerber, J. (Eds.), Modification of the Aerial Environment of Crops. Am. Soc. Agric. Eng. Monogr. No. 2, ASAE, St Joseph, MI, pp. 249-277.

Nury, S. N., 2015. Informed implementation of greening as a heat mitigation measure in Melbourne, Australia: a remote sensing study. Ph.D. thesis, Monash University.

Oke, T., 1987. Boundary Layer Climates, 2nd Edition. Routledge, London and New York.

Oliveira, S., Andrade, H., Vaz, T., 2011. The cooling effect of green spaces as a contribution to the mitigation of urban heat: A case study in Lisbon. Building and Environment 46 (11), 2186-2194.

URL http://dx.doi.org/10.1016/j.buildenv.2011.04.034

Oracle, 2016. Java Platform Standard Edition 7 Documentation. http://docs.oracle.com/javase/7/docs/index.html.

Penman, H. L., 1948. Natural evaporation from open water, bare soil and grass. Proc. Roy. Soc. London A193, $120-146$.

Prata, A. J., 1996. A new long-wave formula for estimating downward clear-sky radiation at the surface. Quarterly Journal of the Royal Meteorological Society 122 (533), 1127-1151.

URL http://doi.wiley.com/10.1002/qj . 49712253306

Python Software Foundation, 2016. Python Language Reference, version 2.7.

R Core Team, 2013. R: A Language and Environment for Statistical Computing. URL http: //www.r-project.org/ 
Rademacher, I. F., Nelson, C., 2001. Nitrogen Effects on Leaf Anatomy within the Intercalary Meristems of Tall Fescue Leaf Blades. Annals of Botany 88 (5), 893-903.

URL http://aob.oxfordjournals.org/cgi/doi/10.1006/anbo.2001.1527

Roberts, P., 2005. Yarra Valley Water: 2004 Residential End Use Measurement Study. https://www.yvw.com.au/yvw/groups/public/documents/document/ yvw1001680.pdf.

Rosenfeld, A. H., Romm, J. J., Akbari, H., Pomerantz, M., 1996. Policies to reduce heat islands: Magnitudes of benefits and incentives to achieve them. In: ACEEE Summer Study on Energy Efficiency in Buildings, Pacific Grove, CA, August 25-31, 1996.

Ruth, M., Coelho, D., 2016. Understanding and managing the complexity of urban systems under climate change. Climate Policy 7 (4), $317-336$.

Rutter, A. A. J., Morton, A. J., Robins, P. C., 1975. A PREDICTIVE MODEL OF RAINFALL INTERCEPTION IN FORESTS II . GENERALIZATION OF THE MODEL AND COMPARISON WITH OBSERVATIONS IN SOME CONIFEROUS AND HARDWOOD STANDS. Journal of Applied Ecology 12 (1), 367-380.

Sailor, D. J., Lu, L., 2004. A top-down methodology for developing diurnal and seasonal anthropogenic heating profiles for urban areas. Atmospheric Environment 38 (17), 2737-2748.

Sanusi, R., Johnstone, D., May, P., Livesley, S. J., 2016. Street Orientation and Side of the Street Greatly Influence the Microclimatic Benefits Street Trees Can Provide in Summer. Journal of Environmental Quality 45 (1), 167-74. URL https://dl.sciencesocieties.org/publications/jeq/abstracts/45/1/167

Schlünzen, K. H., Grawe, D., Bohnenstengel, S. I., Schlüter, I., Koppmann, R., 2011. Joint modelling of obstacle induced and mesoscale changes Current limits and challenges. Journal of Wind Engineering and Industrial Aerodynamics 99 (4), 217-225.

URL http://linkinghub.elsevier.com/retrieve/pii/S0167610511000110

Schmid, H. P., 1994. Source areas for scalars and scalar fluxes. Boundary-Layer Meteorology 67 (3), $293-318$.

Seto, K. C., Fragkias, M., Guneralp, B., Reilly, M. K., 2011. A Meta-Analysis of Global Urban Land Expansion. PLoS ONE 6 (8), e23777.

Shashua-Bar, L., Hoffman, M., 2000. Vegetation as a climatic component in the design of an urban street: An empirical model for predicting the cooling effect of urban green areas with trees. Energy and Buildings 31, 221-235.

URL http://www.sciencedirect.com/science/article/pii/S0378778899000183

Shashua-Bar, L., Potchter, O., Bitan, A., Boltansky, D., Yaakov, Y., 2010. Microclimate modelling of street tree species effects within the varied urban morphology in the Mediterranean city of Tel Aviv, Israel. International Journal of Climatology 57 (March 2009), $44-57$. URL http://onlinelibrary.wiley.com/doi/10.1002/joc.1869/abstract

Sierra, A. M., 2012. Measuring and modeling canopy photosynthesis of olive orchards. Msc thesis plant production systems, Instituto de Agricultura Sostenible (IAS - CSIC).

Simmons, M., Bertelsen, M., Windhager, S., Zafian, H., 2011. The performance of native and non-native turfgrass monocultures and native turfgrass polycultures: An ecological approach to sustainable lawns. Ecological Engineering 37 (8), 1095-1103.

Simpson, J. R., McPherson, E. G., 1993. Potential of tree shade for reducing residental energy use in California. Journal of Arboriculture 22 (1), $10-18$.

Soux, A., Voogt, J. A., Oke, T. R., 2004. A model to calculate what a remote sensor 'sees' of an urban surface. Boundary-Layer Meteorology $111(1), 109-132$

Spangenberg, J., Shinzato, P., 2008. Simulation of the influence of vegetation on microclimate and thermal comfort in the city of São Paulo. Revista SBAU 4, 1-19. URL http://www.revsbau.esalq.usp.br/artigos_cientificos/artigo36.pdf

Stewart, I. D., Oke, T. R., 2012. Local Climate Zones for Urban Temperature Studies. Bulletin of the American Meteorological Society 93 (12), 1879-1900.

URL http://journals.ametsoc.org/doi/abs/10.1175/BAMS-D-11-00019.1

Thorsson, S., Lindberg, F., Björklund, J., Holmer, B., Rayner, D., 2011. Potential changes in outdoor thermal comfort conditions in Gothenburg, Sweden due to climate change: The influence of urban geometry. International Journal of Climatology 31 (2), 324-335.

Tsiros, I. X., 2010. Assessment and energy implications of street air temperature cooling by shade tress in Athens (Greece) under extremely hot weather conditions. Renewable Energy 35 (8), 1866-1869.

URL http://linkinghub.elsevier.com/retrieve/pii/S0960148110000054

UNDESA, 2015. World Urbanization Prospects: The 2014 Revision. https://esa.un.org/unpd/wup/.

Wang, Y., Leuning, R., 1998. A two-leaf model for canopy conductance, photosynthesis and partitioning of available energy I: Model description and comparison with a multi-layered model. Agricultural and Forest Meteorology 91, 89-111.

Wang, Y. P., Jarvis, P. G., 1990. Description and validation of an array model - MAESTRO. Agricultural and Forest Meteorology 51, 257-280.

Weiss, A., Norman, J. M., 1985. Partitioning solar radiation into direct and diffuse, visible and near-infrared components. Agricultural and Forest Meteorology 34 (2-3), 205-213.

WHO, 2016. World Health Organization — Urban Population Growth. http://www.who.int/gho/urban_health/situation_trends/urban_population_growth_text/en/.

Williams, M., Bond, B. J., Ryan, M. G., 2001. Evaluating different soil and plant hydraulic constraints on tree function using a model and sap flow data from ponderosa pine. Plant, Cell and Environment 24 (7), 679-690. URL http://doi.wiley.com/10.1046/j.1365-3040.2001.00715.x

Willmott, C. J., 1981. On the Validation of Models. Physical Geography 2 (2), 184-194.

Winkler, J. A., Guentchev, G. S., Liszewska, M., Perdinan, S., Tan, P. N., 2011. Climate Scenario Development and Applications for Local/Regional Climate Change Impact Assessments: An Overview for the Non-Climate Scientist: Part II: Considerations When Using Climate Change Scenarios. Geography Compass 5 (6), 301-328.

Wong, T. H. F., Brown, R. R., 2009. The water sensitive city: principles for practice. Water Science and Technology 60 (3), 673-82. URL http://www.ncbi.nlm.nih.gov/pubmed/19657162

Wouters, H., Demuzere, M., Ridder, K. D., Nicole, P. M., 2013. The impact of impervious water-storage parameterization on urban climate modelling. Urban Climate 11, 24-50. URL http://dx.doi.org/10.1016/j.uclim.2014.11.005 
Wright, I. J., Westoby, M., 2000. Cross-species relationships between seedling relative growth rate, nitrogen productivity and root vs leaf function in 28 Australian woody species. Functional Ecology 14 (1), 97-107.

Yaghoobian, N., Kleissl, J., Krayenhoff, E. S., 2010. Modeling the Thermal Effects of Artificial Turf on the Urban Environment. Journal of Applied Meteorology and Climatology 49 (3), 332-345.

URL http://journals.ametsoc.org/doi/abs/10.1175/2009JAMC2198.1

Yamada, T., Koike, K., 2011. Downscaling mesoscale meteorological models for computational wind engineering applications. Journal of Wind Engineering and Industrial Aerodynamics 99 (4), 199-216.

URL http://linkinghub.elsevier.com/retrieve/pii/S0167610511000262

Yu, J., Chen, L., Xu, M., Huang, B., 2012. Effects of Elevated CO2 on Physiological Responses of Tall Fescue to Elevated Temperature, Drought Stress, and the Combined Stresses. Crop Science 52 (4), 1848.

URL https: //www.crops.org/publications/cs/abstracts/52/4/1848

Ylmaz, S., Irmak, M. A., Yilmaz, H., 2007. Determination of climatic differences in three different land uses in the city of Erzurum, Turkey. Building and Environment 42, 1604-1612.

\section{Appendix A. MAESPA vegetation parameterisations}

The first complete parameterisation for VTUF-3D is the olive tree (Olea europaea). It has been selected because it is a species commonly found in gardens in Melbourne, considered suitable for Melbourne's climate conditions (drought tolerant evergreen), and are a recommended species for council street tree planting (City of Port Phillip, 2010). In addition, observations of parameters are available from Coutts (2014). The physical and meteorological parameters for a $5 \times 5$ meter grid square are given in Table A1. Physiology parameter values are shown in Table A2. The second complete parameterisation for VTUF-3D is the brushbox tree (Lophostemon Confertus). This tree is chosen because it is the most common street tree in Melbourne (Frank et al., 2006), where all of the evaluation observations data sets are based. This tree has also been the basis of a number of research projects in Melbourne, providing a parameterisation through Coutts et al. (2016a) and Coutts et al. (2015a). The third complete parameterisation for VTUF-3D is for grass, tall fescue (Festuca arundinacea), a common turf grass. This is an important parameterisation for modelling urban environments as a significant portion of urban surfaces are grass. As will be seen in the VTUF-3D evaluation (forthcoming paper), estimates of observed grass cover, for example in an evaluation based on observations from Preston in Melbourne (Coutts et al., 2007; Nury, 2015), range from $11 \%$ to $23 \%$.

This parameterisation is an adaptation of the normal MAESPA tree parameterisations. In it, the vegetation is modelled as a box shaped canopy with a crown height of 0.2 meters. The 0.2 value was taken from the literature, and represents the blade length of the grass. While the crown height for grass is set to $0.2 \mathrm{~m}$, in reality, lawn grass does not grow perfectly perpendicular to the ground, so the blade length is actually longer than perceived. In addition, not all urban lawns are well maintained and closely manicured. Further, while grass is accounted for in the model, though may be slightly overestimated, other vegetation such as shrubs were not accounted for, so in any event, the long grass blade length accounts for some effects of not accounting for shrubs and other urban understory items. This and the rest of the physical and meteorological parameters for a $5 \times 5$ meter grid square are given in Table A1, with physiology parameter values (Table A2) taken from the literature. 
Table A1: MAESPA parameterisations of structural characteristics for Olea europaea, Lophostemon Confertus, and Festuca arundinacea, tree dimensions for an example $5 \times 5 \mathrm{~m}$ grid (that are rescaled for taller/shorter modelled trees).

\begin{tabular}{|c|c|c|c|c|c|c|}
\hline & \multicolumn{2}{|c|}{ Olea europaea } & \multicolumn{2}{|c|}{ Lophostemon Confertus } & \multicolumn{2}{|c|}{ Festuca arundinacea } \\
\hline Parameter & Value & Source & Value & Source & Value & Source \\
\hline crown radius $(\mathrm{m})$ & 2.5 & Coutts (2014) & 2.5 & $\begin{array}{l}\text { Coutts et } \quad \text { al. } \\
(2016 a)\end{array}$ & 2.5 & $\begin{array}{l}\text { Radius of } 5 \times 5 \mathrm{~m} \\
\text { grid }\end{array}$ \\
\hline crown height $(\mathrm{m})$ & 3.75 & Coutts (2014) & 3.75 & $\begin{array}{lll}\text { Coutts } & \text { et } & \text { al. } \\
(2016 a) & & \\
\end{array}$ & 0.2 & $\begin{array}{l}\text { Simmons et al. } \\
(2011)\end{array}$ \\
\hline trunk height (m) & 1.25 & Coutts (2014) & 1.25 & $\begin{array}{l}\text { Coutts et al. } \\
(2016 a)\end{array}$ & 0.01 & \\
\hline $\begin{array}{l}\text { leaf area index } \\
\left(\mathrm{m}^{2} \mathrm{~m}^{-2}\right)\end{array}$ & 2.48 & $\begin{array}{l}\text { Mariscal et al. } \\
(2000)\end{array}$ & 2.0 & $\begin{array}{l}\text { Wright and West- } \\
\text { oby }(2000)\end{array}$ & 7.13 & $\begin{array}{l}\text { ave. from Bijoor } \\
\text { et al. (2014) }\end{array}$ \\
\hline crown shape & round & & round & & box & \\
\hline$z_{H t}(\mathrm{~m})$ & 40.0 & $\begin{array}{l}\text { Forcing data } \\
\text { height }\end{array}$ & 4.0 & $\begin{array}{l}\text { Forcing data } \\
\text { height }\end{array}$ & 4.0 & $\begin{array}{l}\text { Forcing data } \\
\text { height }\end{array}$ \\
\hline$z_{P D}(\mathrm{~m})$ & 2.5 & $\begin{array}{l}2 / 3 \text { of crown } \\
\text { height (Grim- } \\
\text { mond and Oke, } \\
1999)\end{array}$ & 2.5 & $\begin{array}{l}2 / 3 \text { of crown } \\
\text { height (Grim- } \\
\text { mond and Oke, } \\
1999)\end{array}$ & 0.066 & $\begin{array}{l}2 / 3 \text { of crown } \\
\text { height (Grim- } \\
\text { mond and Oke, } \\
1999)\end{array}$ \\
\hline$z_{0, H t}(\mathrm{~m})$ & 0.375 & $\begin{array}{l}1 / 10 \text { of crown } \\
\text { height (Grim- } \\
\text { mond and Oke, } \\
1999)\end{array}$ & 0.375 & $\begin{array}{l}1 / 10 \text { of crown } \\
\text { height (Grim- } \\
\text { mond and Oke, } \\
1999)\end{array}$ & 0.02 & $\begin{array}{l}1 / 10 \text { of crown } \\
\text { height (Grim- } \\
\text { mond and Oke, } \\
\text { 1999) }\end{array}$ \\
\hline
\end{tabular}


Table A2: MAESPA parameterisations of species physiology for Olea europaea, Lophostemon Confertus, and Festuca arundinacea, with parameter values taken from cited literature sources.

\begin{tabular}{|c|c|c|c|c|c|c|}
\hline & \multicolumn{2}{|c|}{ Olea europaea } & \multicolumn{2}{|c|}{ Lophostemon Confertus } & \multicolumn{2}{|c|}{ Festuca arundinacea } \\
\hline Parameter & Value(s) & Source & Value(s) & Source & Value(s) & Source \\
\hline $\begin{array}{l}\text { Soil reflectance (\%PAR, } \\
\% \text { NIR, and \%IR) }\end{array}$ & $\begin{array}{l}0.10 \\
0.05 \\
0.05\end{array}$ & $\begin{array}{l}\text { Levinson et al. } \\
\text { (2007); } \text { Oke } \\
(1987)\end{array}$ & $\begin{array}{l}0.04 \\
0.35 \\
0.05\end{array}$ & Fung-yan (1999) & $\begin{array}{l}0.10 \\
0.05 \\
0.05\end{array}$ & $\begin{array}{l}\text { Observed, Levin- } \\
\text { son et al. (2007), } \\
\text { Oke (1987) }\end{array}$ \\
\hline $\begin{array}{ll}\text { Leaf } & \text { transmittance } \\
(\% \text { PAR, } & \% \text { NIR, and } \\
\% \text { IR) } & \end{array}$ & $\begin{array}{l}0.01 \\
0.28 \\
0.01\end{array}$ & $\begin{array}{lll}\text { Baldini } & \text { et } & \text { al. } \\
(1997) & & \end{array}$ & & & $\begin{array}{l}0.05 \\
0.45 \\
0.01\end{array}$ & $\begin{array}{l}\text { C3 grasses, from } \\
\text { Katjacnik et al. } \\
(2014)\end{array}$ \\
\hline $\begin{array}{l}\text { Leaf reflectance (\%PAR, } \\
\% \text { NIR, and \%IR) }\end{array}$ & $\begin{array}{l}0.08 \\
0.42 \\
0.05\end{array}$ & $\begin{array}{l}\text { Baldini et al. } \\
(1997)\end{array}$ & & & $\begin{array}{l}0.05 \\
0.65 \\
0.08\end{array}$ & $\begin{array}{l}\text { C3 grasses, from } \\
\text { Katjacnik et al. } \\
(2014)\end{array}$ \\
\hline $\begin{array}{lr}\begin{array}{l}\text { Minimum } \\
\text { conductance }\end{array} & \text { gtomatal } \\
\left.\mathrm{m}^{-2} \mathrm{~s}^{-1}\right) & \end{array}$ & 0.03 & Coutts (2014) & 0.01 & $\begin{array}{l}\text { Coutts et al. } \\
(2016 \mathrm{a})\end{array}$ & 0.0 & $\begin{array}{l}\text { De Kauwe et al. } \\
\text { (2015) }\end{array}$ \\
\hline Slope parameter g1 & 2.615 & Coutts (2014) & 3.33 & $\begin{array}{l}\text { Coutts et al. } \\
(2016 \mathrm{a})\end{array}$ & 5.25 & $\begin{array}{l}\text { C3 grasses, from } \\
\text { De Kauwe et al. } \\
\text { (2015) }\end{array}$ \\
\hline $\begin{array}{l}\text { \# of sides of the leaf with } \\
\text { Stomata }\end{array}$ & 1 & $\begin{array}{l}\text { Fernández et al. } \\
\text { (1997) }\end{array}$ & 1 & $\begin{array}{l}\text { Beardsell and } \\
\text { Considine (1987) }\end{array}$ & 2 & $\begin{array}{lll}\text { Green } & \text { et } & \text { al. } \\
(1990) & & \end{array}$ \\
\hline Width of leaf (m) & 0.0102 & & 0.05 & $\begin{array}{lll}\begin{array}{l}\text { Coutts } \\
(2016 a)\end{array} & \text { et } & \text { al. }\end{array}$ & 0.006 & $\begin{array}{l}\text { Rademacher and } \\
\text { Nelson (2001) }\end{array}$ \\
\hline $\begin{array}{l}\mathrm{CO}_{2} \text { compensation point } \\
\left(\mu \mathrm{mol} \mathrm{m}^{-2} \mathrm{~s}^{-1}\right)\end{array}$ & 55 & Coutts (2014) & 53.06 & $\begin{array}{l}\text { Coutts et al. } \\
(2016 \mathrm{a})\end{array}$ & 57 & $\begin{array}{l}\text { Brown and Mor- } \\
\text { gan (1980) at } 25 \\
\text { degrees }\end{array}$ \\
\hline $\begin{array}{l}\text { Max rate electron } \\
\text { transport }(\mathrm{Jmax})(\mu \mathrm{mol} \\
\left.\mathrm{m}^{-2} \mathrm{~s}^{-1}\right)\end{array}$ & 112.4 & Coutts (2014) & 105.76 & $\begin{array}{l}\text { Coutts et al. } \\
(2016 \mathrm{a})\end{array}$ & 80.95 & $\begin{array}{l}\text { Tall Fescue from } \\
\text { Yu et al. (2012) }\end{array}$ \\
\hline $\begin{array}{l}\text { Max rate rubisco activity } \\
(\mathrm{VCmax})\left(\mu \mathrm{mol} \mathrm{m} \mathrm{m}^{-2} \mathrm{~s}^{-1}\right)\end{array}$ & 81.18 & Coutts (2014) & 81.6 & $\begin{array}{lll}\begin{array}{l}\text { Coutts } \\
(2016 a)\end{array} & \text { et } & \text { al. }\end{array}$ & 36.14 & $\begin{array}{l}\text { Tall Fescue from } \\
\text { Yu et al. (2012) }\end{array}$ \\
\hline $\begin{array}{l}\text { Curvature of the light re- } \\
\text { sponse curve }\end{array}$ & 0.62 & Coutts (2014) & 0.61 & $\begin{array}{l}\begin{array}{l}\text { Coutts } \\
(2016 \mathrm{a})\end{array} \\
\text { et }\end{array}$ & 0.7 & $\begin{array}{l}\text { Gilmanov et al. } \\
(2007)\end{array}$ \\
\hline $\begin{array}{l}\text { Activation energy of } \\
\operatorname{Jmax}\left(\mathrm{KJ} \mathrm{mol}^{-1}\right)\end{array}$ & 35350 & $\begin{array}{l}\text { Díaz-Espejo et al. } \\
\text { (2006) }\end{array}$ & 35350 & $\begin{array}{l}\text { Bernacchi et al. } \\
(2001)\end{array}$ & 65300 & $\begin{array}{l}\text { Bernacchi et al. } \\
(2001)\end{array}$ \\
\hline $\begin{array}{l}\text { Deactivation energy of } \\
\mathrm{Jmax}\left(\mathrm{J} \mathrm{mol}^{-1}\right)\end{array}$ & 200000 & $\begin{array}{l}\text { Medlyn et al. } \\
(2005)\end{array}$ & 200000 & $\begin{array}{l}\text { Medlyn et al. } \\
(2005)\end{array}$ & 200000 & $\begin{array}{l}\text { Medlyn et al. } \\
(2005)\end{array}$ \\
\hline Entropy term $\left(\mathrm{KJ} \mathrm{mol}^{-1}\right)$ & 644.4338 & $\begin{array}{l}\text { Medlyn et al. } \\
(2005)\end{array}$ & 644.4338 & $\begin{array}{l}\text { Medlyn et al. } \\
(2005)\end{array}$ & 644.4338 & $\begin{array}{l}\text { Medlyn et al. } \\
(2005)\end{array}$ \\
\hline $\begin{array}{l}\text { Quantum yield of elec- } \\
\text { tron transport (mol elec- } \\
\text { trons } \mathrm{mol}^{-1} \text { ) }\end{array}$ & 0.19 & Sierra (2012) & 0.06 & 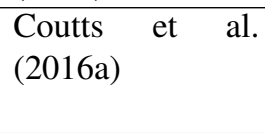 & 0.05 & $\begin{array}{l}\text { Monson et al. } \\
(1982)\end{array}$ \\
\hline $\begin{array}{l}\text { Dark respiration }(\mu \mathrm{mol} \\
\left.\mathrm{m}^{-2} \mathrm{~s}^{-1}\right)\end{array}$ & 0.94 & Coutts (2014) & 1.29 & $\begin{array}{lll}\begin{array}{l}\text { Coutts } \\
(2016 a)\end{array} & \text { et al. }\end{array}$ & 0.6 & $\begin{array}{l}\text { Estimated for Tall } \\
\text { Fescue from Yu } \\
\text { et al. (2012) }\end{array}$ \\
\hline $\begin{array}{l}\begin{array}{l}\text { Specific leaf } \\
\left(\mathrm{mm}^{2} \mathrm{~kg}^{-1}\right)\end{array}\end{array}$ & 5.1 & $\begin{array}{l}\text { Mariscal et al. } \\
(2000)\end{array}$ & 25.3 & $\begin{array}{l}\text { Wright and West- } \\
\text { oby (2000) }\end{array}$ & 23.16 & $\begin{array}{l}\text { Average from Ta- } \\
\text { ble } 1 \text { in Bijoor } \\
\text { et al. (2014) for } 3 \\
\text { turfgrasses. }\end{array}$ \\
\hline
\end{tabular}

